\title{
An Extended Multiple Criteria Data Envelopment Analysis Model
}

\author{
Adel Hatami-Marbini* \\ Department of Strategic Management and Marketing \\ De Montfort University \\ Hugh Aston, The Gateway, Leicester LE1 9BH, UK \\ E-mail: adel.hatamimarbini@dmu.ac.uk
}

\author{
Mehdi Toloo \\ Department of Systems Engineering, Faculty of Economics, \\ Technical University of Ostrava, Sokolska tř. 33, 70121 Ostrava 1, \\ Ostrava, Czech Republic \\ E-mail: mehdi.toloo@vsb.cz \\ URL: http://homel.vsb.cz/ tol0013/
}

Citation: Hatami-Marbini, A. and Toloo, M. (2017) An extended multiple criteria data envelopment analysis model. Expert Systems with Applications, 73, pp. 201-219

*Corresponding author 


\title{
An Extended Multiple Criteria Data Envelopment Analysis Model
}

\begin{abstract}
Several researchers have adapted the data envelopment analysis (DEA) models to deal with two inter-related problems: weak discriminating power and unrealistic weight distribution. The former problem arises as an application of DEA in the situations where decision-makers seek to reach a complete ranking of units, and the latter problem refers to the situations in which basic DEA model simply rates units $100 \%$ efficient on account of irrational input and/or output weights and insufficient number of degrees of freedom. Improving discrimination power and yielding more reasonable dispersion of input and output weights simultaneously remain a challenge for DEA and multiple criteria DEA (MCDEA) models. This paper puts emphasis on weight restrictions to boost discriminating power as well as to generate true weight dispersion of MCDEA when a priori information about the weights is not available. To this end, we modify a very recent MCDEA models in the literature by determining an optimum lower bound for input and output weights. The contribution of this paper is sevenfold: first, we show that a larger amount for the lower bound on weights often leads to improving discriminating power and reaching realistic weights in MCDEA models due to imposing more weight restrictions; second, the procedure for sensitivity analysis is designed to define stability for the weights of each evaluation criterion; third, we extend a weighted MCDEA model to three evaluation criteria based on the maximum lower bound for input and output weights; fourth, we develop a superefficiency model for efficient units under the proposed MCDEA model in this paper; fifth, we extend an epsilon-based minsum BCC-DEA model to proceed our research objectives under variable returns to scale (VRS); sixth, we present a simulation study to statistically analyze weight dispersion and rankings between five different methods in terms of non-parametric tests; and seventh, we demonstrate the applicability of the proposed models with an application to European Union member countries.

Keywords: Data envelopment analysis (DEA); Multiple criteria DEA (MCDEA); Discriminating power; Simulation.
\end{abstract}

\section{Introduction}

Data envelopment analysis (DEA) is a non-parametric frontier methodology, based on linear programming, aiming at measuring the relative efficiency of peer decision-making units (DMUs) 
with multiple inputs and multiple outputs. Farrell (1957) made a start on DEA in the economics literature by defining a simple measure for efficiency that could account for multiple inputs through the context of technical, allocative and productive efficiency. Charnes et al. (1978) and Banker et al. (1984) extended Farrell's idea to propose the CCR (hharnes, $\underline{\text { Cooper, }} \underline{\mathrm{R} h o d e s)}$ and BCC (ㅡanker, Charnes, $\underline{\text { Cooper}) ~ m o d e l s ~ u n d e r ~ c o n s t a n t ~ r e t u r n s ~ t o ~ s c a l e ~(C R S) ~ a n d ~ v a r i a b l e ~}$ returns to scale (VRS) assumptions, respectively. Since 1978, DEA has received a great deal of attention in the literature of Operations Research and Management Science (Cook \& Seiford, 2009; Emrouznejad et al., 2008; Hatami-Marbini et al., 2011).

The relative efficiency of each DMU is defined as a quotient of the weighted sum of outputs to the weighted sum of inputs. The key idea behind DEA is to allow flexibility in the choice of weights on inputs and outputs endogenously per DMU, presenting the (in-)efficiency measure in its best light. The flexibility on weights in DEA allows each DMU to freely consider a set of weights, which may be economically or preferentially unrealistic. On the one hand, such freedom leads to omitting some inputs/outputs by assigning zero weights in the evaluation process. On the other hand, the unfair or undesirable weight distribution among variables gives the opportunity to some units to become efficient by assigning extremely large weights in a single output and/or extremely small weights in a single input.

The DEA models enable to partition all the DMUs into two sets: efficient and inefficient, where an efficient and inefficient DMU achieve a score of 1 and less than 1, respectively. However, it is not too far-fetched to observe certain cases that decision-makers (DMs) seek a complete ranking beyond the dichotomized grouping of units. The lack of discrimination as a limitation of DEA has been theoretically and practically discussed in the literature, in particular, this issue most likely occurs when the number of DMUs is not sufficient enough compared to the total number of inputs and outputs, this is known as a rule of thumb in DEA (Toloo \& Tichy 2015). An effective way for improving the discrimination power and providing more realistic dispersed weights is to reduce the flexibility of input and output weights by incorporating value judgments into the DEA models (Dyson et al., 2001).

There has been a series of research studies adapting the distinct DEA models to circumvent the two aforesaid inter-related problems; weak discriminating power and unrealistic weight distribution. All research work can be categorized into three categories. The first category deals with the problem of discrimination that occurs in practice particularly if there are a 
relatively large number of variables with respect to DMUs. The majority of this category is made up of approaches that are the combination of DEA and multiple-criteria decision making (MCDM) models or DEA and statistical methods particularly the bootstrapping methodology in Simar and Wilson (2000). The main purpose of MCDM is to identify the most preferred alternative in the presence of conflicting criteria that need to be evaluated in making decisions. An MCDM problem can be reformulated in terms of DEA when replacing DMU with alternatives, outputs with criteria to be maximized, inputs with criteria to be minimized. The existing similarity between DEA and MCDM techniques has led the researchers to develop several interactive methods (e.g. see Doyle \& Green, 1993; Stewart, 1994, 1996). To avoid the discrimination problem, Kneip et al. (1998) and Simar and Wilson (2000) developed an alternative method with more discriminating power based on the statistical properties of the nonparametric estimators, in which the number of DMUs must be augmented exponentially compared to the number of input and output variables. However, it is not possible to obtain a given amount of mean-square error in terms of the number of DMUs because the convergence of the nonparametric estimators is dependent on unknown smoothing constants. Nevertheless, a single input and single output system requires at least 25 DMUs, and ideally more than 100 for the confidence intervals of the efficiency estimator to be almost reliable. In reality, large samples are not available at large, hence, there may be a need to think of other discrimination improving methodologies.

The second category makes an attempt to control input and output weights with or without the prior judgments with the aim of reaching more reasonable weight distribution. The most widely used approaches that require a prior information about the weights include absolute multiplier restrictions (Roll et al. 1991), assurance regions (Thompson et al., 1990; Cook and Zhu, 2008) and non-homogeneous weight restrictions (Podinovski, 2004a), and the most widely published approaches without a prior information about the weights include cross-efficiency (Sexton et al. 1986; Doyle and Green, 1994; Hatami-Marbini et al. 2016), super-efficiency (Andersen \& Petersen, 1993) and common set of weights (Hosseinzadeh Lotfi et al. 2013, and Hatami-Marbini et al. 2015). There is a significant body of literature that investigates how to incorporate value judgments in DEA by means of weight restrictions (Podinovski and Thanassoulis, 2007; Cook and Seiford, 2009). However, though the use of weights restriction 
and value judgments in DEA such as assurance region (AR) method leads to more realistic weight distribution, the prior information is not often available and easily applied in practice.

The third category is composed of a few research studies that aim at addressing discrimination problem and unrealistic weight distribution simultaneously. This category considers multiple evaluation criteria to determine the inefficiency measures based on a deviation variable. Sexton et al. (1986) first introduced a deviation variable as an inefficiency measure for each DMU and then minimized the weighted sum of all deviations to provide a final ranking. In line with Sexton et al. (1986), Stewart (1996) utilized the concept of deviation variable to present a minimax DEA model where its objective function was the minimax of all deviation variables. Although Sexton et al. (1986) and Stewart (1996) designed the baseline of research in this category, the study of Li \& Reeves (1999) in the literature is known as a pioneering line of research at presenting a general model frequently called multiple criteria DEA (MCDEA). Li \& Reeves (1999) introduced a MCDEA model with an aim at improving discrimination power compared to the classical DEA models as well as reaching more reasonable weights. The MCDEA model involves three criteria (or objective functions) so as to minimize the inefficiency measure of the DMUs. These criteria have been adapted from the models presented by Charnes et al. (1978), Belton \& Vickers (1993) and Stewart (1996). Li \& Reeves (1999) took into account one of three efficiency criteria based on the purpose of a study to evaluate the DMUs.

Bal et al. (2010) tried to solve the three-objective linear programming model of Li \& Reeves (1999) using a goal programming DEA (GPDEA) approach under CRS and VRS assumptions in order to improve discriminatory power of DEA as well as to generate more realistic input and output weights. However, Ghasemi et al. (2014) showed that the GPDEA models suffer from some mathematical and conceptual flaws. In addition, although Ghasemi et al. (2014) proposed a bi-objective MCDEA (BiO-MCDEA) model involving only two criteria of the model of Li \& Reeves (1999) to improve discriminating power and achieve better weight dispersion, their method contains three flaws. The first flaw is that Ghasemi et al. (2014) assumed a non-Archimedean epsilon as a lower bound for inputs and output weights in their model and mistakenly claimed that the results of the BiO-MCDEA model will not suffer if the lower bound of weights is substituted with zero. The second flaw concerns the weighted sum method used by Ghasemi et al. (2014) to solve the bi-objective programming model where there 
is no clear argument for defining the weights assigned to each objective function. Relying on a decision-maker's opinion for defining these weights can be the basis of conflict since Ghasemi et al. (2014)'s model as a special model proposed by Li \& Reeves (1999) does not allows value judgments in a process of DEA analysis. As the last flaw, Ghasemi et al. (2014) claimed that the minsum BCC-DEA model was incorrectly formulated by Bal et al. (2010) but they did not propose any alternative to deal with the problem.

In this study, we address the gap in previous research by dealing with both weak discriminating power and unrealistic weight distribution simultaneously as inter-connected problems, especially in the circumstances where decision-makers are interested in a complete ranking and more realistic weight distribution rather than the relative efficiency measures of DMUs using basic DEA models. To this end, we first highlight the role of non-Archimedean epsilon in the BiO-MCDEA model of Ghasemi et al. (2014) when additional preferential information about the weights is not available (c.f. aforesaid first flaw). In this respect, we propose a method to determine the optimum epsilon value that can be considered in $\mathrm{BiO}$ MCDEA model as a lower bound of weights with the aim of improving discriminating power and reaching more reasonable or desirable input and output weights dispersion simultaneously. Second, the impact of the importance of each objective function in the linearized bi-objective linear programming model is studied with sensitivity analysis (c.f. aforesaid second flaw). Third, we generalize our method to treat those problems that require the three evaluation criteria at once as proposed by Li \& Reeves (1999). Fourth, we propose a super-efficiency model based on the optimum epsilon to rank the efficient units due to the fact that the main goal of our paper is to provide a complete ranking. Fifth, we argue that Ghasemi et al. (2014)'s claim on the minsum BCC-DEA model is basically flawed. Accordingly, some constructive remarks are provided to remedy their shortcomings as well as to propose an epsilon-based minsum BCC-DEA model. Sixth, we place great emphasis on a comprehensive statistical analysis according to a simulation study with the aim of demonstrating the importance of defining a proper lower bound for weights in the distinct DEA models. We finally present an application to 23 European Union member countries to draw the applicability of the proposed models.

The rest of this paper is organized as follows: In Section 2, we review the conventional DEA and MCDEA models. A motivating example is given in Section 3 to illustrate the role of the non-Archimedean epsilon in the weighted BiO-MCDEA model. In Section 4, we first 
propose a new method to refine the BiO-MCDEA model based on the optimal lower bound for input and output weights. We then propose a model composed of three evaluation criteria along with proposing a model for ranking the efficient DMUs. In Section 5, we first highlight the shortcoming of BiO-MCDEA model and then present a minsum DEA model under VRS assumption. Section 6 presents a simulation study to implement some statistical tests for verifying the applicability of the proposed method. Section 7 presents a real world dataset of the 23 European Union member countries for evaluating the carbon efficiency using the proposed models in this study and existing models in the literature. Finally, we conclude this study with some directions for future research in Section 8.

\section{Background}

This section is divided into two sub-sections to present some preliminaries about the conventional DEA and MCDEA models.

\subsection{Basic DEA models}

The aim of DEA is to estimate the technology or the production possibility set (PPS) according to the minimal extrapolation principle (Charnes et al., 1978). DEA uses a set of producing units, referred to as decision-making units (DMUs), to construct a production or efficiency frontier involving all possible linear combinations of efficient producing units (so-called isoquant).

Assume that there exist $n$ DMUs where every $\operatorname{DMU}_{j \in\{1, . ., n\}}$ consumes $m$ controllable inputs $\left(x_{1 j}, \ldots, x_{m j}\right)$ to produce $s$ outputs $\left(y_{1 j}, \ldots, y_{s j}\right)$. The efficiency score of a DMU under CRS assumption is defined as the ratio of weighted sum of outputs to the weighted sum of inputs subject to the condition that the same ratio for all DMUs must be equal to or less than 1 . In terms of mathematics, the input-oriented CCR model (also called multiplier model) can be formulated as follows (Charnes et al., 1978):

$$
\begin{aligned}
& \max \theta=\sum_{r=1}^{s} u_{r} y_{r o} \\
& \text { s.t. } \\
& \sum_{i=1}^{m} v_{i} x_{i o}=1, \\
& \begin{array}{l}
\sum_{r=1}^{s} u_{r} y_{r j}-\sum_{i=1}^{m} v_{i} x_{i j} \leq 0, \quad j=1, \ldots, n, \\
v_{i} \geq 0, \quad i=1, \ldots, m, \\
u_{r} \geq 0, \quad r=1, \ldots, s .
\end{array}
\end{aligned}
$$

where $\theta_{o}^{*}$ is the efficiency score of the DUM under evaluation, $\mathrm{DMU}_{o \in\{1, \ldots, n\}}$, and $v_{i}$ and $u_{r}$ are the multipliers (weights) assigned to the $i^{\text {th }}$ input and to the $r^{\text {th }}$ output, respectively. 
Definition 1: $\mathrm{DMU}_{o}$ is efficient if $\theta^{*}=1$ and there exists at least one optimal $\left(\boldsymbol{v}^{*}, \boldsymbol{u}^{*}\right)$ of model (1) with $v_{i}^{*}>0, \forall i$ and $u_{r}^{*}>0, \forall r$; otherwise it is inefficient.

To obtain a set of strictly positive weights, Charnes et al. (1979) proposed to impose a positive lower bound on weights for improving the CCR model (1) as follows:

$$
\begin{aligned}
& \max \theta=\sum_{r=1}^{s} u_{r} y_{r o} \\
& \text { s.t. } \\
& \sum_{i=1}^{m} v_{i} x_{i o}=1, \\
& \sum_{r=1}^{s} u_{r} y_{r j}-\sum_{i=1}^{m} v_{i} x_{i j} \leq 0, \quad j=1, \ldots, n, \\
& v_{i} \geq \varepsilon, \quad i=1, \ldots, m, \\
& u_{r} \geq \varepsilon, \quad r=1, \ldots, s,
\end{aligned}
$$

where the parameter $\varepsilon(>0)$ is a non-Archimedean infinitesimal, which prevents weights from being zero. Note that model (2) may be infeasible for an unsuitable value of epsilon. That is because Charnes et al. (1993) stated “... if one uses a small number in place of the infinitesimal epsilon, one is caught between Scylla and Charybdis, i.e. for decent convergence to an optimum, the numerical zero tolerance should be as large as possible, whereas the numerical value approximating the infinitesimal should be as small as possible!". In addition, we draw the attention to the fact that different epsilons in model (2) may lead to different efficiency scores or rankings. The strictly positive weights obtained from model (2) makes the definition of an efficient unit easier: $\mathrm{DMU}_{o}$ is efficient if and only if $\theta^{*}=1$. However, the identification of a suitable value for epsilon plays an important role in this definition (See Amin \& Toloo, 2004).

In general, weight restrictions may lead to the infeasibility of DEA models (Dyson et al. 2001; Sarrico and Dyson, 2004; Podinovski; 2004a, 2004b; Saati et al. 2012; Toloo 2014a). To deal with the problem, Podinovski (2004b) proposed two ways to incorporate the information about production trade-offs between the inputs and outputs into the DEA models. In addition, Estellita Lins et al. (2007) suggested an approach to establish feasibility conditions for DEA multiplier programs. Recently, Podinovski and Bouzdine-Chameeva (2013) showed that the problem of infeasibility is only one of several possible problems that may occur in the presence of weight restrictions. The authors illustrated that the use of weight restrictions may lead to zero or negative efficiency scores of some operating units in which the production set with trade-offs involves free and/or unlimited production.

In this study, we deploy the absolute weight bounds as a special case of the unlinked nonhomogeneous weight restrictions that have been used in several applications such as highway 
maintenance patrols (Cook et al. 1991), implementations of robotics in 31 companies (Cook et al. 1992) and tax collecting departments (Dyson and Thanassoulis, 1988). The basic challenge in this case is the procedures for determining the bounds. For instance, the lower bounds for the output weights for evaluating the efficiency of tax collecting departments (Dyson and Thanassoulis, 1988) were computed based on the average costs of generating a unit of output. It should be also emphasized that the use of non-homogeneous weight restrictions includes some limitations such as vague managerial meaning of the resulting efficiencies that makes it less attractive in real-world problems (see Podinovski (2015) for a detailed discussion). One also faces an awkward situation regarding unlinked weight restrictions when the inconsistency observes between the defined restrictions (Podinovski and Bouzdine-Chameeva, 2013). Our special contribution in this paper is to present a model to compute an optimum value for the lower bounds of weights that does not result in free and unlimited production.

\section{2. $M C D E A$}

The multiplier DEA model has been developed based on a single criterion, which is the maximization of the ratio of the weighted sum of outputs to the weighted sum of inputs. In this regard, DEA provides extreme flexibility in the identification of the weights on inputs and outputs. In other words, each DMU can take the advantage of "weight flexibility" to improve its efficiency score per se as much as possible. In spite of the advantage of allowing such flexibility, the weight flexibility allows zero or very small multipliers to a number of inputs and/or outputs to be used in calculating the relative efficiency of distinct DMUs. Therefore, unreasonable or undesirable weight distribution such as ignoring some inputs and/or outputs of a DMU may not be acceptable in situations where decision-makers are interested in scrutinizing the input and output weights.

Besides, the model with weight flexibility does not often succeed to discriminate and many DMUs are categorized as efficient. Many different methods can be found in the literature with the aim of how weight flexibility can be intentionally controlled in DEA models to deal effectively with the above-mentions obstacles. Li \& Reeves (1999) improved discriminating power by the extension of a single criterion-based DEA to three criteria as expressed below: 


$$
\begin{aligned}
& \min d_{o}\left(\text { or } \max \sum_{j=1}^{n} u_{r} y_{r o}\right) \\
& \min d_{\max } \\
& \min \sum_{j=1}^{n} d_{j} \\
& \text { s.t. } \\
& \sum_{i=1}^{m} v_{i} x_{i o}=1, \\
& \sum_{r=1}^{s} u_{r} y_{r j}-\sum_{i=1}^{m} v_{i} x_{i j}+d_{j}=0, j=1, \ldots, n, \\
& d_{\max }-d_{j} \geq 0, \\
& d_{j} \geq 0, \quad j=1, \ldots, n, \\
& u_{r} \geq 0, \quad r=1, \ldots, s, \\
& v_{i} \geq 0, \quad i=1, \ldots, m,
\end{aligned}
$$

where $d_{o}$, which varies within $[0,1)$, is the deviation variable of $\mathrm{DMU}_{\mathrm{o}}$, and can be considered as an inefficiency measure to be used in computing the efficiency score of $\mathrm{DMU}_{\mathrm{o}}$ as $1-d_{o}$. The first objective function is minimizing the deviation of $\mathrm{DMU}_{\mathrm{o}}$ which is identical to the objective function of the CCR model (1). The other objective functions in model (3) are minimizing the maximum deviation, and minimizing the sum of deviations, respectively. The third set of constraints $\left(d_{\max }-d_{j} \geq 0, j=1, \ldots, n\right)$, which causes the maximum deviation, is redundant for the first and the last criteria. It should be noted that the minimax criterion in comparison with the minsum criterion is more restrictive. Li \& Reeves (1999) argued that the purpose of each study can be independently considered to determine an appropriate efficiency criterion in measuring the efficiency of units. On the other hand, as far as we know, the advance of the MCDEA model (3) has been only carried out based on either minmax or minsum criteria (see Lu \& Lo, 2007).

Bal et al. (2010) recently considered all the three criteria (objective functions) at the same time to provide better-dispersed weights as well as to improve discriminatory power of the MCDEA model (3) under the constant and variable returns to scale technologies. The authors exploited the goal programming to transform the MOLP problems to linear programming problems. However, Ghasemi et al. (2014) showed that the technical flaws in Bal et al. (2010) models fundamentally invalidate their claims, particularly “...improvement of the dispersion of input-output weights and the improvement of discrimination power...".

Contrary to Bal et al. (2010), Ghasemi et al. (2014) developed a weighted BiO-MCDEA model by using the weighted sum (WS) method as G $=\min w_{1} d_{o}+w_{2} d_{\max }+w_{3} \sum_{j=1}^{n} d_{j}$ where $w_{1}+w_{2}+w_{3}=1$ in order to simultaneously render better-dispersed weights and better discriminating power. However, Ghasemi et al. (2014) considered only the two latter 
components and removed $w_{1} d_{o}$ from their proposed model since they believed that the first objective function establishes lower discrimination power in comparison with the other two objective functions. The model of Ghasemi et al. (2014) is expressed as follows:

$$
\begin{aligned}
& \mathrm{z}(\varepsilon)=\min w_{2} d_{\max }+w_{3} \sum_{j=1}^{n} d_{j} \\
& \text { s.t. } \\
& \sum_{i=1}^{m} v_{i} x_{i o}=1, \\
& \sum_{r=1}^{s} u_{r} y_{r j}-\sum_{i=1}^{m} v_{i} x_{i j}+d_{j}=0, j=1, \ldots, n, \\
& d_{\max }-d_{j} \geq 0, \\
& d_{j} \geq 0, \quad j=1, \ldots, n, \\
& u_{r} \geq \varepsilon, \quad r=1, \ldots, s, \\
& v_{i} \geq \varepsilon, \quad i=1, \ldots, m .
\end{aligned}
$$

$\mathrm{DMU}_{o}$ is said to be efficient if $d_{o}^{*}=0$ where $d_{o}^{*}$ is the optimal solution obtained from (4). Otherwise, it is said to be inefficient and the inefficiency score of $\mathrm{DMU}_{j}$ is calculated as $1-d_{j}^{*}$. It should be noted that if we use the weighted goal programming method, the corresponding objective function is identical to the WS method.

The set of constraints of model (4) is identical to model (3). However, the non-negativity of multipliers are changed to $u_{r} \geq \varepsilon, r=1, \ldots, s$ and $v_{i} \geq \varepsilon, \quad i=1, \ldots, m$ where $\varepsilon$ is the nonArchimedean epsilon. These constraints can be considered as weight restrictions. Ghasemi et al. (2014) did not provide any approach to find a suitable value for the epsilon. Moreover, by the use of a dataset, it was showed that in the case of setting $\varepsilon=0$ the weighted BiO-MCDEA model is still robust (Ghasemi et al., 2014, p. 645). Podinovski, and Bouzdine-Chameeva (2013) showed that linked weight restrictions (those that include both input and output weights in one inequality) may be problematic for some sets of DMUs and unproblematic for other sets. Although the weight restrictions $u_{r} \geq \varepsilon$ and $v_{i} \geq \varepsilon$ in model (4) are unlinked (there include input weights and output weights in different $m+s$ inequalities), in Section 4 we will prove that the weight restrictions are consistent and the free and unlimited productions do not occur in the model. In the next section, we present a numerical example to highlight the crucial role of the amount of $\varepsilon$ in the weighted BiO-MCDEA model.

\section{Motivating example}

To illustrate the role of the non-Archimedean epsilon in the weighted BiO-MCDEA model, we utilize a hypothetical data set, which is used in both Bal et al. (2010) and Ghasemi et al. (2014). There are 10 DMUs with four inputs and four outputs represented in Table 1. The results of DEA 
model (1) are given in the last column of Table 1. Due to the fact that the discriminatory power is extremely weak (i.e., 9 efficient DMUs out of 10 DMUs), BiO-MCDEA has been applied to enhance the discriminatory power. To make a fair comparison, analogous to Ghasemi et al. (2014) we assume that $w_{2}=w_{3}$ in this section.

\section{\#\#\#(Insert Table 1 around here)\#\#\#}

Let us first start with $\varepsilon=0$ for weighted BiO-MCDEA as reported in Table 2. In this case, the weight of the fourth output is always zero for all the DMUs and with the exception of $\mathrm{DMU}_{4}$ the weight of the third input is always zero, meaning that these variables, $y_{4}$ and $x_{3}$, are omitted from the efficiency analysis. However, the existence of all the factors such as $y_{4}$ is indispensable to provide a fair assessment across all the units. One of the flaws of the model of Bal et al. (2010) stated by Ghasemi et al. (2014, p. 642) is "...we examined the weights and noticed contrary to what had been claimed in Bal et al. (2010), the input-output weights and efficiency values for some DMUs could attain zero values for all variables..." while the aforementioned result demonstrates that the proposed weighted BiO-MCDEA model by Ghasemi et al. (2014) also suffers from this flaw. This is controversial since Ghasemi et al. (2014, p. 645) claimed that "In the case of setting $\varepsilon=0$, the GPDEA model cannot even generate a value to be above zero; that is, all the efficiency values, input and output weights are zeroes (see Table 15). However, the BiO-MCDEA model did not suffer a similar fate and appeared to be robust."

\section{\#\#\#(Insert Table 2 around here)\#\#\#}

When assuming a positive value for $\varepsilon$, it is clear that the input and output weights do not take zero-value anymore but different values assigned to $\varepsilon$ may lead to fluctuating efficiency score and ranking of each DMU. To describe the problem, we make use of BiO-MCDEA's results for three different epsilons $\varepsilon \in\{0.000 .1,0.001,0.002\}$ in the example as reported in Table 3. We can easily observe the differences between the amount of efficiencies and their rankings for different epsilons. Note that the numbers in the parentheses indicate the ranking of each DMU for a given $\varepsilon$. The exploration of similarity across the set of units shows that $\mathrm{DMU}_{3}$ and $\mathrm{DMU}_{10}$ have identical efficiency score and $\mathrm{DMU}_{6}, \mathrm{DMU}_{7}$ and $\mathrm{DMU}_{9}$ are alike in terms of 
their ranking order in the three cases. However, we can observe many dissimilarities between three cases by reference to Table 3. For example, $\mathrm{DMU}_{1}$ in terms of $\varepsilon \in\{0.000 .1,0.001,0.002\}$ captures the $4^{\text {th }}, 6^{\text {th }}$ and $7^{\text {th }}$ places, respectively. In other words, $\mathrm{DMU}_{1}$ outperforms $\mathrm{DMU}_{2}$ based on $\varepsilon=0.0001$ while the performance of $\mathrm{DMU}_{1}$ is worse than $\mathrm{DMU}_{2}$ according to $\varepsilon=0.001$ and $\varepsilon=0.002$. It is also clarified that the efficiency score of a DMU might be decreased when the value of epsilon is increased. More importantly, in the case of $\varepsilon=0.0001$ and $\varepsilon=0.001, \mathrm{DMU}_{4}$ is efficient whereas this unit is downgraded to the $5^{\text {th }}$ rank when $\varepsilon=0.002$.

\section{\#\#(Insert Table 3 around here)\#\#}

The aim of BiO-MCDEA model proposed by Ghasemi et al. (2014) was to propose better-dispersed weights and better discrimination power as well as dealing with the flaws in Bal et al. (2010). However, the above descriptions highlight the important role of $\varepsilon$ for providing more meaningful and rational results in the performance evaluation.

\section{Methodology}

In this section, we first introduce a model to calculate the maximum value of $\varepsilon$ such that the weighted BiO-MCDEA model always has a feasible solution. Then, we propose an alternative weighted MCDEA method, which is a function of $\varepsilon$, with an aim of improving dispersed weights and discrimination power along with empathizing the role of $\varepsilon$ in MCDEA.

The previous section illustrated that increasing the value of epsilon in model (4) might decrease the efficiency score of a DMU and subsequently increase the discriminating power of the model. In general, let $S(\varepsilon)$ be the feasible region of model (4) for a given $\varepsilon$, i.e. $S(\varepsilon)=$ $\left\{\left(\boldsymbol{v}, \boldsymbol{u}, \boldsymbol{d}, d_{\text {max }}\right): \boldsymbol{v} \boldsymbol{x}_{o}=1, \boldsymbol{u} \boldsymbol{y}_{j}-\boldsymbol{v} \boldsymbol{x}_{j} \leq 0 \forall j, d_{\max }-d_{j} \geq 0 \forall j, \boldsymbol{u} \geq \boldsymbol{\varepsilon}_{s}, \boldsymbol{v} \geq \boldsymbol{\varepsilon}_{m}\right\} \quad$ where $\boldsymbol{\varepsilon}_{s}=(\varepsilon, \ldots, \varepsilon) \in R^{S}$. Obviously, if $\varepsilon_{1}<\varepsilon_{2}$, then $S\left(\varepsilon_{1}\right) \supset S\left(\varepsilon_{2}\right)$ which implies $z\left(\varepsilon_{1}\right) \geq z\left(\varepsilon_{2}\right)$. In addition, $S(0)$ is a superset of $S(\varepsilon)$ and $z(0) \geq z(\varepsilon)$ for all $\varepsilon>0$. An easy computation clarifies that there exists $\varepsilon^{*}>0$ such that

$$
S(\varepsilon) \begin{cases}=\phi, & \varepsilon>\varepsilon^{*} \\ \neq \phi, & \varepsilon \leq \varepsilon^{*}\end{cases}
$$

As a result, the maximum discriminating power of model (4) arises when $\varepsilon=\varepsilon^{*}$.

The maximum value of epsilon can be computed using the following integrated linear model (Amin \& Toloo, 2007): 


$$
\begin{array}{ll}
\varepsilon^{*}=\max \varepsilon & \\
\text { s.t. } & j=1, \ldots, n, \\
\sum_{i=1}^{m} v_{i} x_{i j} \leq 1, & \\
\sum_{r=1}^{s} u_{r} y_{r j}-\sum_{i=1}^{m} v_{i} x_{i j} \leq 0, \quad j=1, \ldots, n, \\
\varepsilon-u_{r} \leq 0, \quad r=1, \ldots, s, \\
\varepsilon-v_{i} \leq 0, \quad i=1, \ldots, m,
\end{array}
$$

where $\varepsilon$ is a decision variable. The following theorems are brought out to validate model (5).

Theorem 1: Model (5) is always feasible.

\section{Proof.}

It is sufficient to introduce a feasible solution for the model. Without loss of generality, suppose $\sum_{i=1}^{m} x_{i k}=\max \left\{\sum_{i=1}^{m} x_{i j}: j=1, \ldots, n\right\} . \quad$ Let $\quad v_{i}=\frac{1}{\sum_{i=1}^{m} x_{i k}} \quad$ for $\quad i=1, \ldots, m$, $u_{r}=\min \left\{\frac{\Sigma_{i=1}^{m} x_{i j}}{\left(\Sigma_{r=1}^{s} y_{r j}\right)\left(\sum_{i=1}^{m} x_{i k}\right)}: j=1, \ldots, n\right\}$ for $r=1, \ldots, s$, and $\varepsilon=\min \left\{v_{1}, \ldots, v_{m}, u_{1}, u_{2}, \ldots, u_{s}\right\}$. It is easy to verify that $(\boldsymbol{v}, \boldsymbol{u}, \varepsilon)$ is a feasible solution for model (5). $\square$

Theorem 2: $0<\varepsilon^{*} \leq \frac{1}{\max \left\{\sum_{i=1}^{m} x_{i j}: j=1, \ldots, n\right\}}$.

\section{Proof.}

By reference to the given feasible solution in the proof of Theorem $1, \varepsilon^{*}>0$. Then, multiplying the constraint $\varepsilon-v_{i} \leq 0$ by $x_{i j}$ for $i=1, \ldots, m$ and summing up the results over $j$ from $j=1$ to $j=n$ gives a finite upper bound for the non-Archimedean epsilon: $\varepsilon \leq \frac{\sum_{i=1}^{m} v_{i} x_{i j}}{\sum_{i=1}^{m} x_{i j}} \leq \frac{1}{\sum_{i=1}^{m} x_{i j}}$ for $j=1, \ldots, n$ or equivalently $\varepsilon^{*} \leq \frac{1}{\max \left\{\sum_{i=1}^{m} x_{i j}: j=1, \ldots, n\right\}}$.

Theorem 3: Model (4) is (i) feasible for $\varepsilon \leq \varepsilon^{*}$ and (ii) infeasible for $\varepsilon>\varepsilon^{*}$.

\section{Proof.}

(i) Let $\left(\overline{\boldsymbol{v}}, \overline{\boldsymbol{u}}, \varepsilon^{*}\right)$ be an optimal solution of model (5). Furthermore, let $\bar{d}_{j}=\sum_{i=1}^{m} \bar{v}_{i} x_{i j}-$ $\sum_{r=1}^{s} \bar{u}_{r} y_{r j}$ for $j=1, \ldots, n$ and $\bar{d}_{\max }=\max \left\{\sum_{i=1}^{m} \bar{v}_{i} x_{i j}-\sum_{r=1}^{s} \bar{u}_{r} y_{r j}: j=1, \ldots, n\right\}$. It is clear that $\left(\bar{d}_{\text {max }}, \overline{\boldsymbol{d}}, \overline{\boldsymbol{v}}, \overline{\boldsymbol{u}}\right)$ is a feasible solution for model (4) for all $\varepsilon \leq \varepsilon^{*}$.

(ii) Suppose, on contrary to our claim, $\left(d_{\max }, \boldsymbol{d}, \boldsymbol{v}, \boldsymbol{u}\right)$ is a feasible solution for $\varepsilon>\varepsilon^{*}$. Hence, $(\boldsymbol{v}, \boldsymbol{u}, \varepsilon)$ is a feasible solution for model (5) with a larger objective function value than $\left(\overline{\boldsymbol{v}}, \overline{\boldsymbol{u}}, \varepsilon^{*}\right)$ which contradicts the optimality condition. As a result, model (4) is infeasible for $\varepsilon>\varepsilon^{*}$.

Podinovski (2004b) extended the links between weight restrictions in multiplier forms to the dual envelopment forms. He interpreted the constraints of the envelopment model as 
production trade-offs, which signify concurrent changes to inputs and/or outputs in the technology. Taking into account the trade-offs may extend the production technology. In this case, over and above the feasibility of DEA models, two important issues as regards production technology may arise; free and unlimited production. Technology $T$ allows free production of the semi-positive vector of outputs $\boldsymbol{y}_{o}$ if $\left(\mathbf{0}_{m}, \boldsymbol{y}_{o}\right) \in T^{1}$, and technology $T$ allows unlimited production of the vector of outputs $\boldsymbol{y}_{o}$ if there exists a vector of inputs $\boldsymbol{x}_{o}$ such that $\left(\boldsymbol{x}_{o}, \alpha \boldsymbol{y}_{o}\right) \in$ $T$ for all $\alpha \geq 0$ (For more details see Podinovski and Bouzdine-Chameeva (2013)).

If there is a free production, the obtained efficiency scores cannot be trusted. Podinovski and Bouzdine-Chameeva (2013) stated some approaches to test whether free or unlimited production occurs. In this respect, Theorem 4 shows that model (4) does not suffer from the free and unlimited production issues.

Theorem 4. The free and unlimited productions do not occur in model (4).

\section{Proof.}

Let $\left(\boldsymbol{v}^{*}, \boldsymbol{u}^{*}, \boldsymbol{d}^{*}, d_{\text {max }}^{*}\right)$ be an optimal solution for model (4). It is sufficient to verify that the efficiency score of DMU under evaluation is a positive number or equivalently $d_{o}^{*}<1$. From the constrains of model (4) we have $d_{o}^{*}=1-\boldsymbol{u}^{*} \boldsymbol{y}_{o}$ where $\boldsymbol{v}^{*} \boldsymbol{x}_{o}=1$. On the other hand, we have $u_{r}^{*} \geq \varepsilon^{*}>0, \boldsymbol{y}_{o} \geq \mathbf{0}_{s}$ and $\boldsymbol{y}_{o} \neq \mathbf{0}_{s}$ and subsequently $\boldsymbol{u}^{*} \boldsymbol{y}_{o}>0$ which completes the proof. Note that we can acquire a strictly positive optimal weight $\boldsymbol{u}^{*}>\mathbf{0}_{s}$ such that $\boldsymbol{v}^{*} \boldsymbol{x}_{j}>0$ which are two necessary conditions to avoid free and unlimited production issues (see Theorem 8 in Podinovski and Bouzdine-Chameeva (2013)).

We point out that the lower bound for weights imposed by $\varepsilon$ in model (5) forestalls weights from being zero. The optimal solution of model (5) for the data set shown in Table 1 is $\varepsilon^{*}=0.00238$, which is a maximum value according to Theorem 3. Ghasemi et al. (2014) considered this example with $\varepsilon=0.0001$ in terms of their alleged claim on improving discriminatory power without thinking of the role of epsilon. However, Table 4 shows an increase in discrimination between ten DMUs when $\varepsilon^{*}=0.00238$ in comparison with $\varepsilon=$ 0.0001. In other words, according to Table 3 for $\varepsilon=0.0001,30 \%$ of DMUs are efficient whereas we can improve it by $10 \%$ when $\varepsilon$ is assumed to be 0.00238 . More interestingly, the efficient $\mathrm{DMU}_{4}$ in the case of $\varepsilon=0.0001$ declines to the $5^{\text {th }}$ place in the ranking order when

${ }^{1} \mathbf{0}_{m}$ is the origin in $\mathbb{R}^{m}$. 
$\varepsilon^{*}=0.00238$. Model (4) might still result in more than one efficient DMU in the presence of the best epsilon (see the last column of Table 4).

\section{\#\#\#(Insert Table 4 around here)\#\#}

Let us now study the dispersion of input and output weights using the coefficient of variation (CV) (Ghasemi et al., 2014; Bal et al., 2010). The CV can be defined as the ratio of the standard deviation to the absolute value of the mean, i.e., $\mathrm{CV}=\sigma /|\mu|$, and showed the extent of variability in relation to the mean of the obtained optimal weights. It should be noted that $|\mu|$ as a denominator of the $\mathrm{CV}$ is always positive in the context of efficiency measure. It is a useful and informative statistic for comparing the degree of variation from one data series to another, even if the means are drastically different from each other. The higher the CV leads to the greater the dispersion in the variable. The $\mathrm{CV}$ has a unit invariant property and this allows us to be

compared to each other rather than other measures such as standard deviations and mean (Koopmans et al. 1964). It is possible to obtain the CV by using two different ways; CV $=\sigma /|\mu|$ where

$$
\begin{aligned}
\mu_{j} & =\frac{\sum_{r=1}^{s} u_{r j}+\sum_{i=1}^{m} v_{i j}}{m+s}, \forall j \\
\sigma_{j} & =\frac{\left(\sum_{r=1}^{s} u_{r j}-\mu\right)^{2}+\left(\sum_{i=1}^{m} v_{i j}-\mu\right)^{2}}{m+s}, \forall j
\end{aligned}
$$

$$
\begin{aligned}
\mu_{i} & =\frac{\sum_{j=1}^{n} v_{i j}}{n}, \forall i \\
\sigma_{i} & =\frac{\left(\sum_{j=1}^{n} v_{i j}-\mu\right)^{2}}{n}, \forall i
\end{aligned} \quad \begin{aligned}
& \mu_{r}=\frac{\sum_{j=1}^{n} u_{r j}}{n}, \forall r \\
& \sigma_{r}=\frac{\left(\sum_{j=1}^{n} u_{r j}-\mu\right)^{2}}{n}, \forall r
\end{aligned}
$$

Bal et al. (2010) used the former method to compute the CVs for their analysis but, unfortunately, it is not clear whether Ghasemi et al. (2014, p.649) deployed the former or latter method in their statistical analysis. In this paper, we apply the former method as well to ensure consistency of results. In this example, the average of the CVs with $\varepsilon=0, \varepsilon=0.0001$ and $\varepsilon=0.00238$ are $1.08734,1.07425,0.72236$, respectively. In terms of the CV, the DEA model with $\varepsilon=0$ has the greatest weight dispersion that seems bizarre since according to Bal et al. (2010, p. 99) the weight dispersion problem pops up when some DMUs are evaluated as efficient with extreme or zero values for the input and output weights (see the columns related to $v_{3}$ and 
$u_{4}$ in Table 2). As a result, it is tough to infer that the $\mathrm{CV}$ is a reliable proxy to show the weight dispersion. In spite of the fact that the CV may not be intact, it will be used for our simulation study to assess robustness.

Bal et al. (2010) applied the goal programming to three criteria of Li \& Reeves (1999) aiming at presenting the improvement of the dispersion of input and output weights and Ghasemi et al. (2014) underlined the flaws of the models of Bal et al. (2010). However, Ghasemi et al. (2014) disregarded the goal programming method and used the simple WS method to aggregate the three objective functions without explaining their whys and wherefores. In addition, Ghasemi et al. (2014) omitted the first objective function, $\min d_{o}$ (or $\max \sum_{j=1}^{n} u_{r} y_{r o}$ ), because (i) Li \& Reeves (1999) showed that this criterion provides lower discrimination power when compared with two other criteria (ii) one element of minsum criterion is the $d_{o}$ criterion.

By reference to Tables 2 and 3 in the $1^{\text {st }}$ numerical example of Li \& Reeves (1999), it has been demonstrated that the weights assigned to inputs and outputs in $\min d_{o}$ are more dispersed as compared with the classical DEA. What's more, Li \& Reeves (1999) investigated the effect of each criterion independently while the purpose of the weighted BiO-MCDEA model proposed by Ghasemi et al. (2014) is to aggregate all criteria. We also believe that when $d_{o}$ (i.e., the deviation of the DMU under evaluation) exists twice in the aggregated weighted objective functions, it leads us to the conclusion that $d_{o}$ twice as important as the other deviations. All in all, it motivates us to propose the following epsilon-based weighted MCDEA model:

$$
\begin{aligned}
& w(\varepsilon)=\min w_{1}\left(2 d_{o}\right)+w_{2} d_{\max }+w_{3} \sum_{\substack{j=1 \\
j \neq o}}^{n} d_{j} \\
& \text { s.t. } \\
& \sum_{i=1}^{m} v_{i} x_{i o}=1, \\
& \sum_{r=1}^{s} u_{r} y_{r j}-\sum_{i=1}^{m} v_{i} x_{i j}+d_{j}=0, j=1, \ldots, n, \\
& d_{\max }-d_{j} \geq 0, \\
& d_{j} \geq 0, \quad j=1, \ldots, n, \\
& u_{r} \geq \varepsilon, \quad r=1, \ldots, s, \\
& v_{i} \geq \varepsilon, \quad i=1, \ldots, m,
\end{aligned}
$$

where $\varepsilon$ is the optimal solution of model (5). $\mathrm{DMU}_{o}$ is said to be efficient if $d_{o}^{*}=0$ where $d_{o}^{*}$ is the optimal solution obtained from (6). Otherwise, it is said to be inefficient and the efficiency score of inefficient $\mathrm{DMU}_{j}$ is calculated as $1-d_{j}^{*}$. Compellingly, to the extent that the weighted goal programming and WS methods to solving model (3) are identical, model (6) can be also recognized as a corrected model of Bal et al. (2010). Let us return to the numerical example (see 
Table 1). The result of model (6) with $\varepsilon=0.00238$ is reported in Table 5 . Contrary to the weighted BiO-MCDEA model, the difference in rankings of a number of DMUs can be recognized in Table 5. For instance, $\mathrm{DMU}_{1}$ is improved by two places from $7^{\text {th }}$ in weighted $\mathrm{BiO}$ MCDEA to $5^{\text {th }}$ in weighted MCDEA in the ranking of DMUs (see Tables 4 and 5). To solve the proposed models, we use GAMS software (See Appendix).

\section{\#\#\#(Insert Table 5 around here)\#\#\#}

Theorem 5. The objective function value of model (6) is bounded.

\section{Proof.}

We first prove that model (6) is always feasible. Let $\left(\boldsymbol{v}^{*}, \boldsymbol{u}^{*}\right)$ be the optimal solution of multiplier form of CCR model with $\varepsilon^{*}$. Note that Cooper et al. (2007) proved that such solution exists. In this respect, a vector $\left(\boldsymbol{v}^{0}, \boldsymbol{u}^{0}, \boldsymbol{d}^{0}, d_{\text {max }}^{0}\right)$ is a feasible solution of model (6) where

$$
v_{i}^{0}=v_{i}^{*}, u_{r}^{0}=u_{r}^{*}, d_{j}^{0}=\left\{\begin{array}{ll}
\sum_{i=1}^{m} v_{i}^{*} x_{i j}-\sum_{r=1}^{s} u_{r}^{*} y_{r j}, j \neq o \\
1-\sum_{r=1}^{s} u_{r}^{*} y_{r o},
\end{array}, d_{\max }^{0}=\max \left\{d_{j}^{0} \mid j=1, \ldots, n\right\} .\right.
$$

The objective function is non-negative on account of a non-negative linear combination of the two positive terms. Due to the fact that model (6) is a min-type problem the proof completes.

Models (4) and (6) can be classified as an a posteriori method since distinct weights for the objectives make up a set of Pareto optimal solutions and it is supposed to be identified the most preferred ones by the $\mathrm{DM}(\mathrm{s})$. To provide informative and insightful results for the DM, we can solve the models repeatedly for the different weights, $w_{\mathrm{i}}(i=1,2,3)$. For model (4) involving $\mathrm{w}_{2}$ and $\mathrm{w}_{3}\left(=w_{2}-1\right)$, it can be solved for $w_{2}=0$ and $w_{3}=1$ as a start point, then, $\mathrm{w}_{2}$ is increasing and $w_{3}$ is decreasing by 0.01 in each step. That is to say, we require 101 times of solving the model for each unit. Ghasemi et al. (2014) paid no attention to the weights of the objective functions $w_{\mathrm{i}}(\mathrm{i}=1,2,3)$ and only set equal objectives in their assessment. Note that we can employ the similar procedure for model (6) to perform weights analysis on the three objective functions, meaning that one of three weights is first fixed by a given value and the above-mentioned method will be implemented for the two outstanding weights.

The results reported in Table 4 are based on the equal weights $\left(w_{2}=w_{3}\right)$. Under the maximum epsilon, we think of the above algorithm using a trade-off between $w_{2}$ and $w_{3}$ in 
model (4) to highlight the importance of the pre-determined weight associated with each objective function in computing the efficiency measures as shown in Figure 1.

\section{\#\#\#(Insert Figure 1 around here)\#\#\#}

Figure 1 provides additional insight for making a decision about the objective weights and the ranking of the DMUs. As shown in Figure 1, $\mathrm{DMU}_{3}$ and $\mathrm{DMU}_{10}$ are always efficient (i.e. $d_{3}^{*}=d_{10}^{*}=0$ ) for all the combinations of weights. The amount of $w_{2}$ and $w_{3}$ has no effect on $\mathrm{DMU}_{9}$ and this DMU is located in the most inferior rank all the time as depicted in Figure 1. More interestingly, the left side of the vertical solid red line in Figure 1 indicates a robust region, meaning that the ranking of the DMUs prior to step $6\left(\mathrm{w}_{2}=0.56\right.$ and $\left.\mathrm{w}_{3}=0.44\right)$ preserves unchanged. However, the ranking instability can be showed in the right side of the vertical red line in Figure 1. By moving from step 1 to step 10 (i.e., increasing $w_{2}$ and decreasing $w_{3}$ ) provides two situations for each DMU: increasing or declining its rank. For instance, the rank of $\mathrm{DMU}_{5}$ is declined from the $3^{\text {rd }}$ to the $7^{\text {th }}$ by increasing $w_{2}$ (see Figure 1 ).

To provide a complete ranking across the efficient DMUs (i.e., $d_{j}^{*}=0$ ) such as $\mathrm{DMU}_{3}$ and $\mathrm{DMU}_{10}$ in the example, we exploit the super-efficiency concept in DEA to propose the following model:

$$
\begin{aligned}
& p(\varepsilon)=\min w_{2} d_{\text {max }}+w_{3}\left(\sum_{\substack{j=1 \\
j \neq o}}^{n} d_{j}-\sum_{r=1}^{s} u_{r} y_{r o}\right) \\
& \text { s.t. } \\
& \sum_{i=1}^{m} v_{i} x_{i o}=1, \\
& \sum_{r=1}^{s} u_{r} y_{r j}-\sum_{i=1}^{m} v_{i} x_{i j}+d_{j}=0, \quad j=1, \ldots, n ; j \neq o, \\
& d_{\max }-d_{j} \geq 0, \\
& d_{j} \geq 0, \quad j=1, \ldots, n ; j \neq 0, \ldots, n ; j \neq o, \\
& u_{r} \geq \varepsilon, \quad r=1, \ldots, s, \\
& v_{i} \geq \varepsilon, \quad i=1, \ldots, m,
\end{aligned}
$$

where $\varepsilon$ is the optimal solution of model (5). Note that the objective function of model (7) can be

changed to $p(\varepsilon)=\min w_{2} d_{\max }+w_{3} \sum_{j=1}^{n} d_{j}-2 w_{1} \sum_{r=1}^{s} u_{r} y_{r o}$ regarding model (6) where $w_{1}=\frac{w_{3}}{2}$.

Theorem 6. Model (7) is feasible.

\section{Proof.}


Let $\left(\boldsymbol{v}^{0}, \boldsymbol{u}^{0}\right)$ be a feasible solution of super-efficiency model with $\varepsilon^{*}$ under CRS assumption. It is clear on inspection that $\left(\boldsymbol{v}^{0}, \boldsymbol{u}^{0}, \boldsymbol{d}^{0}, d_{\text {max }}^{0}\right)$ is a feasible solution of model (7) where $d_{j}^{0}=$ $\sum_{i=1}^{m} v_{i}^{0} x_{i j}-\sum_{r=1}^{s} u_{r}^{o} y_{r j}, d_{\text {max }}^{0}=\max \left\{\sum_{i=1}^{m} v_{i}^{0} x_{i j}-\sum_{r=1}^{s} u_{r}^{o} y_{r j} \mid j=1, \ldots, n\right\}$.

Although during the past years a major effort has been made to treat infeasibility in the super-efficiency DEA models under the assumption of VRS (Seiford \& Zhu, 1999; Lovell \& Rouse 2003; Lee et al. 2011), Thrall (1996) and Zhu (1996) also showed that infeasibility of the super-efficiency model under the CRS assumption may occur in a very rare situation (viz. infeasibility occurs when a certain pattern of zero data exists in the inputs and outputs). Therefore, the main body of the DEA literature practically assumes that the super-efficiency models under CRS does not suffer the problem of infeasibility (see e.g., Lee et al. 2011; Pourmahmoud et al. 2016; Aldamak et al. 2016).

Theorem 7. For efficient $\mathrm{DMU}_{o}$, the optimal value of $\sum_{r=1}^{s} u_{r} y_{r o}$ in model (7) is always equal to or greater than unity (i.e., $p(\varepsilon) \geq 1$ ).

\section{Proof.}

Let $\left(\boldsymbol{v}^{*}, \boldsymbol{u}^{*}, \boldsymbol{d}^{*}, d_{\text {max }}^{*}\right) \in \mathbb{R}^{m+s+n+1}$ be the optimal solution of model (4). Given that the feasible region of model (4) is more restricted than model (7), the optimal objective function value of (4) is equal to or greater than (7). Let us think of the two following cases:

(i) If the constraint $\sum_{r=1}^{s} u_{r} y_{r o}-\sum_{i=1}^{m} v_{i} x_{i o}+d_{o}=0$ is redundant in model (4), then $\left(\boldsymbol{v}^{*}, \boldsymbol{u}^{*}, \boldsymbol{d}_{o}^{*}, d_{\text {max }}^{*}\right) \in \mathbb{R}^{m+s+n} \quad$ is an optimal solution for model (7) where $\boldsymbol{d}_{o}^{*}=\left(d_{1}^{*}, \ldots, d_{o-1}^{*}, d_{o+1}^{*}, \ldots, d_{n}^{*}\right)$ and hence $\sum_{r=1}^{s} u_{r}^{*} y_{r o}=1$.

(ii) If the constraint $\sum_{r=1}^{s} u_{r} y_{r o}-\sum_{i=1}^{m} v_{i} x_{i o}+d_{o}=0$ is tight in model (4), then $\left(\overline{\boldsymbol{v}}^{*}, \overline{\boldsymbol{u}}^{*}, \overline{\boldsymbol{d}}^{*}, \bar{d}_{\text {max }}^{*}\right) \in \mathbb{R}^{m+s+n}$ is an optimal solution of model (7). On contrary to our claim, suppose $\sum_{r=1}^{s} \bar{u}_{r}^{*} y_{r o}<1$ and accordingly $d_{o}^{\prime}=1-\sum_{r=1}^{s} \bar{u}_{r}^{*} y_{r o}(>0)$. It is clear that $\left(\overline{\boldsymbol{v}}^{*}, \overline{\boldsymbol{u}}^{*}, \widetilde{\boldsymbol{d}}^{*}, \bar{d}_{\text {max }}^{*}\right)$ is a feasible solution for model (4) where

$$
\tilde{d}_{j}^{*}= \begin{cases}\bar{d}_{o}^{*}, & j \neq o \\ d_{o}^{\prime}, & j=o\end{cases}
$$

Under these assumptions, the objective value of model (4) for $\left(\boldsymbol{v}^{*}, \boldsymbol{u}^{*}, \widetilde{\boldsymbol{d}}^{*}, d_{\text {max }}^{*}\right)$ is less than the optimal objective value which is not possible. 
As previously noted, based on the epsilon-based model (4) the efficiency of $\mathrm{DMU}_{3}$ and $\mathrm{DMU}_{10}$ remains unchanged for all the combinations of $w_{2}$ and $w_{3}$. We use model (7) to differentiate between these efficient units and $\mathrm{DMU}_{3}$ is superior to $\mathrm{DMU}_{10}$ because their $p^{*}(\varepsilon)$ are 1.22998 and 1.18218 , respectively.

In short, Figure 2 displays a graphical representation of the proposed methodology with the aim of improving the discriminatory power and weight dispersion simultaneously.

\section{\#\#\#(Insert Figure 2 around here)\#\#\#}

\section{Minsum BCC-DEA model}

Ghasemi et al. (2014, p. 643) also argued the validity of the VRS formulation of Bal et al. (2010). By reference to Appendix C in Ghasemi et al. (2014, p. 648), the authors claimed that the minsum BCC-DEA model (8) are incorrectly formulated due to the absence of $u_{0}$ in its objective function.

$$
\begin{aligned}
& \min \sum_{j=1}^{n} d_{j} \\
& \text { s.t. } \\
& \sum_{i=1}^{m} v_{i} x_{i o}=1, \\
& \sum_{r=1}^{s} u_{r} y_{r j}+u_{0}-\sum_{i=1}^{m} v_{i} x_{i j}+d_{j}=0, j=1, \ldots, n, \\
& d_{j} \geq 0, \quad j=1, \ldots, n, \\
& u_{r} \geq 0, \quad r=1, \ldots, s, \\
& v_{i} \geq 0, \quad i=1, \ldots, m, \\
& u_{0} \text { free in sign. }
\end{aligned}
$$

In addition, though Ghasemi et al. (2014) mentioned the necessity of considering the free variable $u_{0}$ in the objective function of BCC version of models they did not attempt to formulate a corrected GPDEA and minsum BCC-DEA models. However, we believe that the presence of $u_{0}$ in the objective function of model (8) is intuitively incorrect. To show this fact, let us recall the definition of $d_{j}$ in $\frac{\sum_{r=1}^{s} u_{r} y_{r j}+u_{0}}{\sum_{i=1}^{m} v_{i} x_{i j}}+d_{j}=1$ according to Li \& Reeves (1999). Variable $d_{j}$ as a proxy is defined to represent a measure of inefficiency and the smaller value of $d_{o}$ represents the less inefficiency for $\mathrm{DMU}_{\mathrm{o}}$. In other words, the model allows the flexibility in the identification of the input and output weights to minimize the inefficiency of $\mathrm{DMU}_{\mathrm{o}}$ subject to $\frac{\sum_{r=1}^{s} u_{r} y_{r j}+u_{0}}{\sum_{i=1}^{m} v_{i} x_{i j}}+$ $d_{j}=1$. Note that model (8) is unbounded if its objective function is replaced by $\sum_{j=1}^{n} d_{j}+u_{0}$ (see the following Theorem 8). 
Theorem 8. Model (8) is unbounded if its objective function is replaced with $\sum_{j=1}^{n} d_{j}+u_{0}$.

Proof. Due to Theorem 3, model (8) has a feasible solution where $\sum_{j=1}^{n} d_{j}+u_{0}$ is its objective function. Considering the Karush-Kuhn-Tucker optimality conditions for lingering programming problems (Bazaraa et al. 2010), it is sufficient to show that the following dual is infeasible:

$$
\begin{array}{ll}
\max \theta & \\
\text { s.t. } & \\
\theta x_{i o}-\sum_{j=1}^{n} \lambda_{j} x_{i j} \leq 0, & i=1, \ldots, m, \\
\sum_{j=1}^{n} \lambda_{j} y_{r j} \leq 0, & r=1, \ldots, s, \\
\sum_{j=1}^{n} \lambda_{j}=1, & \\
\lambda_{j} \leq 1, \quad j=1, \ldots, n . &
\end{array}
$$

The convexity constraint $\sum_{j=1}^{n} \lambda_{j}=1$ leads to $\sum_{j=1}^{n} \lambda_{j} y_{r j}=y_{r j}, \forall r$ and hence from the constraints $\sum_{j=1}^{n} \lambda_{j} y_{r j} \leq 0, \forall r$, we obtain $y_{r j} \leq 0, \forall r$ which is not possible in DEA.

Ghasemi et al. (2014) asserted that model (8) is wrongly modeled while the only reasoning behind their claim was to make a use of the result of the numerical examples. They applied model (8) to the data set presented in Table 1 and, accordingly the $4^{\text {th }}$ output is wholly overlooked due to the fact that its weight for all DMUs is zero (see Table 6). Likewise, regardless of $\mathrm{DMU}_{4}$, the $3^{\text {rd }}$ and $4^{\text {th }}$ inputs are also removed from the analysis as presented in Table 6.

\section{\#\#(Insert Table 6 around here)\#\#\#}

As we earlier showed under CRS assumption, we need to define the maximum value of $\varepsilon$ as a lower bound of the input and output weights to deal with the problem reported by Ghasemi et al. (2014). In doing so, we propose the following $\varepsilon$-form of the minsum BCC-DEA model:

$$
\begin{aligned}
& \min \sum_{j=1}^{n} d_{j} \\
& \text { s.t. } \\
& \sum_{i=1}^{m} v_{i} x_{i o}=1, \\
& \sum_{r=1}^{s} u_{r} y_{r j}+u_{0}-\sum_{i=1}^{m} v_{i} x_{i j}+d_{j}=0, j=1, \ldots, n, \\
& d_{j} \geq 0, \quad j=1, \ldots, n, \\
& u_{r} \geq \varepsilon, \quad r=1, \ldots, s, \\
& v_{i} \geq \varepsilon, \quad i=1, \ldots, m, \\
& u_{0} \text { free in sign, }
\end{aligned}
$$

where the maximum value of epsilon can be calculated by the following proposed model: 


$$
\begin{aligned}
& \varepsilon^{*}=\max \varepsilon \\
& \text { s.t. } \\
& \sum_{i=1}^{m} v_{i} x_{i j} \leq 1, \quad j=1, \ldots, n, \\
& \sum_{r=1}^{s} u_{r} y_{r j}+u_{0}-\sum_{i=1}^{m} v_{i} x_{i j} \leq 0, j=1, \ldots, n, \\
& \varepsilon-u_{r} \leq 0, \quad r=1, \ldots, s, \\
& \varepsilon-v_{i} \leq 0, \quad i=1, \ldots, m .
\end{aligned}
$$

The optimal value of model (11) is equal to solving the following equation (Toloo, 2012):

$\varepsilon^{*}=\frac{1}{\max \left\{\sum_{i=1}^{m} x_{i j}: j=1, \ldots, n\right\}}$

When solving model (11) for the data set in Table $1, \varepsilon^{*}=0.00356$. Table 7 reports the efficiency score of DMUs by using model (10) with $\varepsilon=\varepsilon^{*}$. Compared to Table 6 , the results in Table 7 show that we can improve discrimination power as well as avoiding assigning zero weights to some inputs/outputs in the presence of the maximum non-Archimedean epsilon.

\section{\#\#\#(Insert Table 7 around here)\#\#\#}

The BCC-DEA results obtained from Ghasemi et al. (2014) reported in Table 6 show that three variables almost drop from the evaluation while the proposed method keeps the necessary influence of all the variables in the evaluation process as shown in Table 7. Some variables take the same weights (0.00356) that are common when assuming the epsilon in the DEA model and it does not convey that a factor with same weights plays a neutral role in the evaluation (Cooper et al. 2007).

In a more general setting, the above model under VRS lends itself both to weighted BiOMCDEA model (4) and weighted MCDEA model (6). It should be noted that, analogous to Theorem 4, it is possible to prove that in the other proposed models (6), (7) and (10) in this study there is no free or unlimited production.

\section{A simulation study}

Simulation is a powerful and experimental tool used by analysts to describe system behavior or real-world process, predict the performance of an existing system by generating random variables as well as to compare alternative solutions for a particular design problem.

In the literature, the use of simulation in DEA can be divided into two streams with the aim of reaching different research objectives. The first line of research presented in (Banker et al., 1993; Smith, 1997; Bardhan et al. 1998; Read and Thanassoulis, 2000; Adler and 
Yazhemsky, 2010) aims to compare the accuracy of the different models according to the "true efficiency" using a Monte Carlo simulation in which one generates a large number of DMUs, based on various production functions, inefficiency distributions, correlation between variables and sample sizes. The consequences on a simulated database are analyzed under various forms of misspecification of the DEA models in order to draw general conclusions with regard to the advantages and disadvantages of the methods being evaluated. The second line of research takes advantage of a Monte Carlo simulation (Bal et al., 2008, 2010) to test the applicability and performance of a DEA model in comparison with other models in a way that a random variate for a random variable is generated by the inverse method. In this regard, the hypotheses for ranking similarity and weight distribution of two certain models are tested based on the resulting rankings and weights from the simulated data. Over and above the studies of Bal et al. (2008, 2010), Shokouhi et al. (2010, 2014) can be also classified into the latter simulation category where the authors used the simulation to analyse the conformity of the rankings of the DMUs resulting from the robust DEA model.

It should be emphasized that our simulation is in line with a recent study studied in Bal et al. (2010) to ensure comparability. In this section, we underline statistically importance of defining a proper lower bound on input and output weights among five models using a simulation analysis.

\subsection{Simulation structure}

The discrimination problem heavily relies on the number of inputs and outputs relative to the number of observations. As such, a relatively large number of input and output variables as compared to DMUs may lead to the majority of observations to be defined as efficient. We hence consider a sample size of 10 DMUs with four inputs and four outputs to ensure comparability with our earlier numerical example taken from Bal et al. (2010) and Ghasemi et al. (2014). To statistically test the hypotheses regarding to the rankings and weight distribution of different models, we randomly generate the unbiased samples as inputs of procedure by the inverse method. In this respect, we take into account five various models including (i) CCR with maximum $\varepsilon\left(\mathrm{CCR}^{\varepsilon^{*}}\right)$, (ii) $\mathrm{BiO}-\mathrm{MCDEA}$ with maximum $\varepsilon\left(\mathrm{BiO}^{\left.-\mathrm{MCDEA}^{\varepsilon^{*}}\right) \text {, (iii) TRI-MCDEA }}{ }^{2}\right.$

\footnotetext{
2 TRI-MCDEA corresponds to model (7).
} 
with maximum $\varepsilon$ (TRI-MCDEA ${ }^{\varepsilon^{*}}$ ), (iv) BiO-MCDEA with $\varepsilon=0.0001$ (BiO-MCDEA ${ }^{\varepsilon=0.0001}$ ), and (v) $\mathrm{CCR}$ with zero $\varepsilon\left(\mathrm{CCR}^{\varepsilon=0}\right)$.

Let inputs $\left(x_{i j}, i=1,2,3,4 ; j=1, \ldots, 10\right)$ and outputs $\left(\underline{y_{r j}}, r=1,2,3,4 ; j=1, \ldots, 10\right)$ be independent random variables with the identical uniform distribution on the interval $[0,100]$. The inverse method as a data generation process is implemented by the RAND function in Microsoft Excel to generate 80000 random numbers. Given that the production process entails four inputs and four outputs, the entire simulated population is 5000 observations and a sample size of 10 DMUs leads to 500 samples. The descriptive statistics of the simulated inputs and outputs for all 500 samples are given in the above part of Tables 8.

\section{\#\#\#(Insert Table 8 around here)\#\#\#}

\subsection{Statistical analysis}

We calculate the efficiency measures and weights of the five models, $\mathrm{CCR}^{\varepsilon^{*}}, \mathrm{BiO}-\mathrm{MCDEA}^{\varepsilon^{*}}$, $\mathrm{TRI}^{-M C D E A}{ }^{\varepsilon^{*}}, \mathrm{BiO}-\mathrm{MCDEA}^{\varepsilon=0.0001}$, and $\mathrm{CCR}^{\varepsilon=0}$ for every sample by means of solving 5000 LPs for each model. The bottom part of Table 8 and Table 9 present the descriptive statistics for the efficiencies and input and output weights of five models, respectively.

\section{\#\#\#(Insert Table 9 around here)\#\#\#}

\subsubsection{Ranking analysis (discriminating power)}

We first obtain the ranking order of the ten DMUs for five models based on their superefficiency scores for a given run. Then, the Spearman's rank correlation and Pearson correlation are applied to assess the strength of the relationship between the rankings of a pair of five models. The Pearson correlation measures the degree of the linear relationship between two variables while the Spearman's rank correlation deals with two ordinal variables. The average value for the Spearman and Pearson correlations based on ranks is identical for each pair of models as reported in Table 8 . For this set of observations, given that we take account of the super-efficiency measures for every model in order to provide the complete ranking, we have no tied ranks to differentiate the Spearman and Pearson correlations. It should be noted that the presence of ties in the rankings causes slightly different between the Spearman and Pearson correlations. As can be seen, the average value for the Spearman and Pearson correlation coefficient for the $\mathrm{CCR}^{\varepsilon^{*}}$ and $\mathrm{CCR}^{\varepsilon=0}$ models is 0.940098 , that shows a very strong positive 
relationship between the rankings of these models. In other words, if $\mathrm{DMU}_{1}$ achieves a higherranking position in comparison with $\mathrm{DMU}_{2}$ in a given model, then we are almost sure that $\mathrm{DMU}_{1}$ is highly ranked in another model. As a result, considering the maximum positive value of the lower bound for weights in the CCR model does not lead to a significant improvement in ranking DMUs. Nevertheless, since the efficiency score of $\mathrm{CCR}^{\varepsilon=0}$ is equal to or larger than $\mathrm{CCR}^{\varepsilon^{*}}$, the discriminating power of $\mathrm{CCR}^{\varepsilon^{*}}$ is equal to or greater than $\mathrm{CCR}^{\varepsilon=0}$, that is, the number of efficient units in $\mathrm{CCR}^{\varepsilon^{*}}$ is equal to or lower than $\mathrm{CCR}^{\varepsilon=0}$. Presumably, a significant relationship exists between the BiO-MCDEA ${ }^{\varepsilon^{*}}$ and TRI-MCDEA ${ }^{\varepsilon^{*}}$ models, i.e. 0.865663. The lowest correlation coefficient (0.299763) between $\mathrm{BiO}-\mathrm{MCDEA}^{\varepsilon=0.0001}$ and $\mathrm{CCR}^{\varepsilon=0}$ indicates a very weak relationship between the ranking of Ghasemi et al. (2014) and CCR models.

\section{\#\#(Insert Table 10 around here)\#\#\#}

In addition, we consider the following null hypothesis to determine the statistical significance of the Spearman and Pearson correlations:

\section{$H_{0}$ : There is no association between the rankings of two models}

Table 11 shows the percentages of failing to reject the null hypothesis $H_{0}$ or achieving a statistically significant Spearman's and Pearson correlation between each pair of the models for $\alpha=5 \%$ and $\alpha=1 \%$ in which the values above the diagonal correspond to $\alpha=5 \%$ and below the diagonal correspond to $\alpha=1 \%$. Overall, in Spearman test the percentages related to $\alpha=5 \%$ is greater than $\alpha=1 \%$ while in Pearson test the percentages related to $\alpha=1 \%$ is greater than $\alpha=5 \%$. According to Table 7, 99\% and 97\% of cases at the 5\% and $1 \%$ levels of significance have a perfect association between the rankings of $\mathrm{CCR}^{\varepsilon *}$ and $\mathrm{CCR}^{\varepsilon=0}$ models. Furthermore, we cannot find a significant association between the rankings of $\mathrm{CCR}^{\varepsilon^{*}}$ and $\mathrm{BiO}-\mathrm{MCDEA}^{\varepsilon^{*}}$. Comparing the findings of these two ranking tests in Table 11 clarifies a perfect relationship between them when the efficiency scores are considered instead of their rankings.

\section{\#\#\#(Insert Table 11 around here)\#\#\#}

\subsubsection{Weight analysis}

Each DEA model generates the weights of inputs and outputs endogenously per DMU. We draw a comparison between weight dispersion over the five models $\left\{\mathrm{CCR}^{\varepsilon^{*}}, \mathrm{BiO}-\mathrm{MCDEA}{ }^{\varepsilon^{*}}\right.$, TRI- 
$\operatorname{MCDEA}^{\varepsilon^{*}}, \mathrm{BiO}-\mathrm{MCDEA}^{\varepsilon=0.0001}$, and $\left.\mathrm{CCR}^{\varepsilon=0}\right\}$ using a test for homogeneity of variances and means on the $\mathrm{CV}$ of weights.

We now take the weight dispersion issue in these models into consideration and compare weights dispersion between each pair of five models. In other words, we consider how dispersed all the input and output weights for each DMU are in a given DEA model where less weight dispersion presumably shows more similarity between the generated endogenous weights for each DMU. In this case, the CV enables us to appreciate weight dispersion for each DMU in each model. Compared to the cognate studies, the similar study can be also found in Ghasemi et al. (2014) and Bal et al. (2010).

We apply two different non-parametric tests involving Levene and Fligner-Killeen tests on the $\mathrm{CV}$ of weights for 500 simulated samples in order to test the following null hypothesis, respectively:

$H_{0}:$ There is no association between weight dispersion of two models

$H_{0}$ : There is no association between weight means of two models

Levene's test for homogeneity - an analysis of variance (ANOVA) based on deviations from group means or group median-was postulated to be quite robust to departures from normality (Levene, 1960; Brown and Forsythe, 1974; Fox, 2008). We perform Levene's test in $R$ based on car package (Fox, 2008) for each pair of models for each simulated data set in which the average of $\mathrm{p}$-value is given in Table 12.

\section{\#\#\#(Insert Table 12 around here)\#\#\#}

We consider both one- and two-sided Levene's tests to identify better-dispersed weights model. Table 13 reports the percentages of failing to reject $H_{0}$ or achieving a statistically significant one- and two-sided Levene between models with the 5\% and $1 \%$ significance levels, in which the values above the diagonal correspond to $\alpha=5 \%$ and below the diagonal correspond to $\alpha=1 \%$.

\#\#(Insert Table 13 around here)\#\#\# 
The null hypothesis is almost accepted for each pair of models in terms of the two-sided Levene's tests (see Table 13). We should mention here that the two-sided Levene's test is designed for testing the equality of variances and to compare the variances we require applying the one-sided Levene's tests. In doing so, we define the following alternative hypothesis:

$H_{1}$ : The weight variance of the first model is less than or equal to the weight variance of the second one $\left(\sigma_{1}^{2}<\sigma_{2}^{2}\right)$.

Let us make a comparison between $\mathrm{CCR}^{\varepsilon^{*}}$ and $\mathrm{CCR}^{\varepsilon=0}$ models, and $\mathrm{BiO}-\mathrm{MCDEA}^{\varepsilon^{*}}$ and BiO-MCDEA ${ }^{\varepsilon=0.0001}$ models to verify the effect of considering a suitable value for the nonArchimedean epsilon. As can be seen in Table 14, the null hypothesis is accepted for both oneand two-sided Levene's tests with 5\% and 1\% levels of confidence for each two pair of models. This therefore statistically shows that defining the maximum value for the non-Archimedean epsilon decreases the variance of weights in the CCR and BiO-MCDEA models.

As it is shown in Table 14, increasing the level of significance leads to decreasing the percentage of failing to reject $H_{0}$ and subsequently the numbers in the above of diagonal is less than the corresponding number in the below of diagonal. Moreover, in each cell of Table 14, the obtained percentage by two-sided test is greater than one-sided test.

Fligner-Killeen test is another tool to verify the homogeneity of variances that is robust against departures from Normality (Conover et al. 1981). In this regard, we perform a version of Fligner-Killeen test in $R$ based on stats package in which median centering is used in each pair of data as the average of the $\mathrm{p}$-value for each pair of the five models are reported in Table 14. Table 15 shows the percentages of failing to reject $H_{0}$ or achieving a statistically significant between each pair of models with the $5 \%$ and $1 \%$ significance levels for one- and two-sided FlignerKilleen test.

\section{\#\#(Insert Tables 14 and 15 around here)\#\#\#}

Based on the result, the cognate null hypothesis for $\mathrm{CCR}^{\varepsilon^{*}}$ and $\mathrm{CCR}^{\varepsilon=0}$ models and $\mathrm{BiO}$ $\operatorname{MCDEA}^{\varepsilon^{*}}$ and BiO-MCDEA ${ }^{\varepsilon=0.0001}$ models is accepted for both one- and two-sided FlignerKilleen test. Consequently, analogous to Levene's test, imposing the maximum value of the nonArchimedean epsilon on the models produces a positive and significant effect on the variance of weights in the CCR and BiO-MCDEA models. 
The summary of what we have carried out in this section is depicted in Figure 3.

\section{\#\#\#(Insert Figure 3 around here)\#\#\#}

\section{An application}

Since 2005, the European Union (EU) has determined climate change as one of the most important challenges in the world in the light of imposing major negative consequences for the environment, economy and society at large. The EU therefore commenced the most ambitious emissions trading program, so-called the EU Emissions Trading Scheme (EU ETS) to cut worldwide emissions of carbon dioxide $\left(\mathrm{CO}_{2}\right)$ within the Kyoto Protocol. According to this program, the individual member states undertake the responsibility for setting targets, allocating permits, determining verification and enforcement in order to decrease greenhouse gas emissions by eight percent (relative to 1990 levels) by 2020. The EU ETS implementation includes three phases based on "cap and trade": a pilot phase (2005-2007), a 5-year commitment period (20082012), and an 8-year commitment period (2013-2020).

In this case study, we evaluate the efficiency of carbon emissions for $25 \mathrm{EU}$ countries in the light of three inputs, installation number $\left(x_{1}\right), \mathrm{CO}_{2}$ allowances $\left(x_{2}\right)$ and gross inland energy consumption $\left(x_{3}\right)$, and two outputs, renewable energy production $\left(y_{1}\right)$ and renewable energy share in transport $\left(y_{2}\right)$ as defined below:

- $x_{1}$ is a number of stationary technical units where one or more activities are executed which can have an influence on pollution,

- $x_{2}$ represents the total amount of certain $\mathrm{CO}_{2}{ }^{3}$ that can be annually emitted by installations,

- $x_{3}$ describes the quantity of energy necessary to satisfy inland consumption of a country under consideration,

- $y_{1}$ represents the percentage of electricity produced from renewable energy sources,

- $y_{2}$ is the degree to which conventional fuels have been substituted by biofuels in the transport sector.

The input and output data for the 25 countries are documented in Table 16 in which the raw data replicated from Ghasemi et al. (2014).

\footnotetext{
${ }^{3} \mathrm{It}$ is measured in tons.
} 


\section{\#\#\#(Insert Table 16 around here)\#\#\#}

We consider the equal weights for the objective functions when applying different models together with scaling all inputs of the 25 countries by the use of their population size to provide a consistent comparison with the method proposed by Ghasemi et al. (2014). The scaling leads to a fair assessment despite the population of countries as well as becoming a remedy for the lack of discriminatory power which may derive from synchronizing volume and percentagebased measures (Dyson et al., 2001).

In what follows, we first implement model (5) to obtain the maximum value for the nonArchimedean epsilon as a lower bound for input and output weights in CCR, BiO- and TRIMCDEA models. The optimal solution to model (5) is $1.221 \times 10^{-4}$. The $2^{\text {nd }}, 3^{\text {rd }}$ and $4^{\text {th }}$ columns of Table 17 present the carbon efficiency of the 25 countries for the CCR, BiO- and TRI-MCDEA models, respectively. Note that the ranking of each country is reported in parentheses. According to the CCR model with the maximum epsilon, \{Austria, France, Latvia, Romania, Spain, Sweden $\}$ are all CCR efficient and cannot differentiate between them any further while \{France, Latvia, Spain $\}$ and \{Latvia, Spain $\}$ are efficiently preforming on the basis of BiO- and TRI-MCDEA models, respectively. Comparing the CCR model with BiO- and TRIMCDEA models, the difference is easily observable where the CCR efficiency is always equal to or greater than $\mathrm{BiO}$ - and TRI-MCDEA efficiency since BiO- and TRI-MCDEA respectively entail one and two extra evaluation measures that enhance the discriminatory power (see the $2^{\text {nd }}$, $3^{\text {rd }}$ and $4^{\text {th }}$ columns of Table 17$)$.

\section{\#\#\#(Insert Table 17 around here)\#\#\#}

By implementing the CCR model in the case of setting $\varepsilon=0$ in lieu of $\varepsilon=1.221 \times$ $10^{-4}$, we yield the carbon efficiency and ranking results for the countries as shown in the $5^{\text {th }}$ column of Table 16. Given that the computed CCR efficiency with zero epsilon is greater than the CCR efficiency with the maximum epsilon, this reflects that the discriminating power of the former case is weaker than the latter case. In other words, Slovakia is also efficient in CCR with $\varepsilon=0$ in addition to $\{$ Austria, France, Latvia, Romania, Spain, Sweden $\}$. The $6^{\text {th }}$ and $7^{\text {th }}$ columns of Table 17 also yield the efficiency and ranking order of the countries by solving the BiOMCDEA model when $\varepsilon$ is set to $10^{-5}$ and 0 , respectively. Comparing the result of three BiO- 
MCDEA models with different values of the epsilon (i.e., $1.221 \times 10^{-4}, 10^{-5}$ and 0 ) demonstrates the fact that by increasing the amount of the epsilon value, the corresponding efficiency score for the countries is not decreased in any case.

To analyze the weight differences in inputs and outputs of distinct models, we show the result of the input and output weights for the 25 countries in Table 18 that are derived from different models.

\section{\#\#\#(Insert Table 18 around here)\#\#\#}

Our proposed method enables us to improve the discrimination power by sensibly and partially reducing the flexibility of input and output weights. We have to note that this study proceeds with a different avenue for improving the discrimination power in which the weights play a crucial role in measuring the efficiency scores.

\section{Conclusions and managerial implications}

In conventional DEA, there is no constraint on the weights of the inputs or outputs and many inefficient units may be misclassified as efficient while in some situations degrees of freedom are scarce. In some cases, decision-makers may be interested in increasing the differentiability among all DMUs and reaching more reasonable weight distribution while conventional DEA may not be sufficiently capable to achieve them, particularly, in the case of a relatively large number of variables in comparison with DMUs. In this paper, we first made an attempt to improve discriminating power as well as to provide more realistic weight dispersion within the MCDEA models. We second revisited the MCDEA model of Li \& Reeves (1999) involving three different objective functions and the weighted BiO-MCDEA model of Ghasemi et al. (2014). We showed that the importance of the non-Archimedean epsilon was neglected in the weighted BiO-MCDEA model. To deal with this shortage, we took into consideration the maximum value for non-Archimedean epsilon in both MCDEA and BiO-MCDEA models in line for improving dispersed weights and discrimination power. Third, sensitivity analysis was implemented to verify the stability for the importance weights of per objective function in our proposed approaches. Fourth, a super-efficiency MCDEA model for efficient units under the optimum epsilon was developed to provide a complete ranking. Fifth, we dealt with the flaws of the minsum BCC-DEA model developed by Ghasemi et al. (2014), by extending a new epsilon- 
based minsum BCC-DEA model. Sixth, a simulation study was presented to statistically analyze weight dispersion and rankings between five different methods in terms of non-parametric tests. Finally, the applicability of the proposed models with an application to European Union member countries was discussed in our research.

The extended approach can be basically applied to various selection and evaluation problems including technology selection (Toloo, 2014b), supplier evaluation (Toloo, 2014c) or the NATO enlargement application (Hatami-Marbini et al., 2013). Often in such applications the concern of the policy-maker or the manager as a decision-maker is to determine the most preferred alternatives. Although DEA models have the capability to make a dichotomized classification, another approach or modification is required to improve the lack of discrimination in DEA applications, in order to provide a complete ranking. Besides, in some situation, the removal of the assessment factors by assigning zero weights may be unacceptable from the management viewpoint. Whilst the modified MCDEA model developed in this paper may not give rise to a complete ranking, we optimally considered the lower bound for input and output weights to further refine the discriminatory power of the DEA models as well as to avoid zero weights in efficiency assessment. We also used the simulation study and the non-parametric tests to show that that imposing the maximum value of the non-Archimedean epsilon on the models provides a positive and significant impact on the variance of weights in the CCR and BiOMCDEA models.

There are a number of challenges involved in the proposed research that provide rich opportunities for future research. A stream of future research can extend our algorithms theoretically to other variations of the DEA methods such as BCC and SBM models. Specifically, the modified MCDEA model can provide a fruitful basis for developing the integrated MCDEA models with common weights. In addition, the principles could be applied to multi-stage evaluation in techno-economic systems such as supply chains studied in Färe and Grosskopf (2000). The developed framework in this study can potentially lend itself to many practical applications. We plan to implement the proposed framework in the real-world and discuss in a follow-up paper demonstrating the practical implications of our model in real-life problems.

\section{References}


Adler, N., \& Yazhemsky, E. (2010). Improving discrimination in data envelopment analysis: PCA-DEA or variable reduction. European Journal of Operational Research, 202(1), 273-284.

Aldamak, A., Hatami-Marbini, A., \& Zolfaghari, S. (2016). Dual frontiers without convexity. Computers \& Industrial Engineering, 101, 466-478.

Amin, G. R., \& Toloo, M. (2004). A polynomial-time algorithm for finding $\varepsilon$ in DEA models. Computers and Operations Research, 31(5), 803-805.

Amin, G. R., \& Toloo, M. (2007). Finding the most efficient DMUs in DEA: An improved integrated model. Computers \& Industrial Engineering, 52(1), 71-77.

Andersen, P., \& Petersen, N. C. (1993). A procedure for ranking efficient units in data envelopment analysis. Management Science, 39(10), 1261-1264.

Bal, H., Örkcü, H. H., \& Çelebioğlu, S. (2008). A new method based on the dispersion of weights in data envelopment analysis. Computers \& Industrial Engineering, 54(3), 502-512.

Bal, H., Örkcü, H. H., \& Çelebioğlu, S. (2010). Improving the discrimination power and weights dispersion in the data envelopment analysis. Computers and Operations Research, 37, 99-107.

Banker, R. D., Charnes, A., \& Cooper, W. W. (1984). Some models for estimating technical and scale inefficiencies in data envelopment analysis. Management science, 30(9), 1078-1092.

Banker, R. D., Gadh, V. M., \& Gorr, W. L. (1993). A Monte Carlo comparison of two production frontier estimation methods: corrected ordinary least squares and data envelopment analysis. European Journal of Operational Research, 67(3), 332-343.

Bardhan, I. R., Cooper, W. W., \& Kumbhakar, S. C. (1998). A simulation study of joint uses of data envelopment analysis and statistical regressions for production function estimation and efficiency evaluation. Journal of Productivity Analysis, 9(3), 249-278.

Belton, V., \& Vickers, S. P. (1993). Demystifying DEA-A visual interactive approach based on multiple criteria analysis. Journal of the Operational Research Society, 44(9), 883-896.

Brown, M. B., \& Forsythe, A. B. (1974). Robust tests for the equality of variances. Journal of the American Statistical Association, 69, 364 - 376.

Charnes, A., Cooper, W. W., \& Rhodes, E. (1978). Measuring the efficiency of decision making units. European Journal of Operational Research, 2, 429-444.

Charnes, A., Cooper, W. W., \& Rhodes, E. (1979). Measuring the efficiency of decision-making units. European Journal of Operational Research, 3(4), 339.

Charnes, A., Rousseau, J., \& Semple, J. (1993). An effective non-Archimedean anti-degeneracy/cycling linear programming method especially for data envelopment analysis and like models. Annals of Operations Research, 46-47(2), 271-278.

Conover W. J., Johnson M. E., \& Johnson M. M. (1981). A comparative study of tests for homogeneity of variances, with applications to the outer continental shelf bidding data. Technometrics, 23, 351-361.

Cook, W. D., \& Seiford, L. M. (2009). Data envelopment analysis (DEA) - Thirty years on. European Journal of Operational Research, 192(1), 1-17. 
Cook, W. D., Johnston, D. A., \& McCutcheon, D. (1992). Implementations of robotics: identifying efficient implementors. Omega, 20(2), 227-239.

Cook, W. D., Kazakov, A., Roll, Y., \& Seiford, L. M. (1991). A data envelopment approach to measuring efficiency: case analysis of highway maintenance patrols. The Journal of Socio-Economics, 20(1), 83103.

Cook, W. D., Liang, L., Zha, Y., \& Zhu, J. (2009). A modified super-efficiency DEA model for infeasibility. Journal of the Operational Research Society, 60(2), 276-281.

Cooper, W. W., Seiford, L. M., \& Tone, K. (2007). Data envelopment analysis: A comprehensive text with models, applications, references and DEA-solver software: Second-editions. Springer.

Doyle, J., \& Green, R. (1993). Data envelopment analysis and multiple criteria decision making. Omega, 21(6), 713-715.

Doyle, J., \& Green, R. (1994). Efficiency and cross-efficiency in DEA: Derivations, meanings and uses. Journal of the operational research society, 45(5), 567-578.

Dyson, R. G., \& Thanassoulis, E. (1988). Reducing weight flexibility in data envelopment analysis. Journal of the Operational Research Society, 39(6), 563-576.

Dyson, R. G., Allen, R., Camanho, A. S., Podinovski, V. V., Sarrico, C. S., \& Shale, E. A. (2001). Pitfalls and protocols in DEA. European Journal of Operational Research, 132(2), 245-259.

Emrouznejad, A., Parker, B. R., \& Tavares, G. (2008). Evaluation of research in efficiency and productivity: A survey and analysis of the first 30 years of scholarly literature in DEA. Socio-Economic Planning Sciences, 42(3), 151-157.

Estellita Lins, M.P., Moreira da Silva, A.C., \& Lovell, C.A.K., (2007). Avoiding infeasibility in DEA models with weight restrictions. European Journal of Operational Research, 181(2), 956-966

Färe, R., \& Grosskopf, S. (2000). Network DEA. Socio-economic planning sciences, 34(1), 35-49.

Farrell, M. J. (1957). The measurement of productive efficiency. Journal of the Royal Statistical Society. Series A (General), 120(3), 253-290.

Fox, J. (2008). Applied regression analysis and generalized linear models. Sage Publications.

Ghasemi, M. R., Ignatius, J., \& Emrouznejad, A. (2014). A bi-objective weighted model for improving the discrimination power in MCDEA. European Journal of Operational Research, 233(3), 640-650.

Hatami-Marbini, A., Agrell, P. J., Tavana, M., \& Khoshnevis, P. (2016). A flexible cross-efficiency fuzzy data envelopment analysis model for sustainable sourcing. Journal of Cleaner Production, forthcoming.

Hatami-Marbini, A., Emrouznejad, A., \& Tavana, M. (2011). A taxonomy and review of the fuzzy data envelopment analysis literature: Two decades in the making. European Journal of Operational Research, 214(3), 457-472.

Hatami-Marbini, A., Tavana, M., Agrell, P. J., Hosseinzadeh Lotfi, F., \& Ghelej Beigi, Z. (2015). A common-weights DEA model for centralized resource reduction and target setting. Computers \& Industrial Engineering, 79, 195-203. 
Hatami-Marbini, A., Tavana, M., Saati, S., \& Agrell, P. J. (2013). Positive and normative use of fuzzy DEA-BCC models: A critical view on NATO enlargement. International Transactions in Operational Research, 20(3), 411-433.

Hosseinzadeh Lotfi, F., Hatami-Marbini, A., Agrell, P. J., Aghayi, N., \& Gholami, K. (2013). Allocating fixed resources and setting targets using a common-weights DEA approach. Computers \& Industrial Engineering, 64(2), 631-640.

Kneip, A., Park, B.U., Simar, L., (1998). A note on the convergence of nonparametric DEA estimators for production efficiency scores. Econometric Theory, 14, 783-793.

Koopmans, L. H., Owen, D. B., \& Rosenblatt, J. I. (1964). Confidence intervals for the coefficient of variation for the normal and log normal distributions. Biometrika, 51, 25-32.

Lee, H. S., Chu, C. W., \& Zhu, J. (2011). Super-efficiency DEA in the presence of infeasibility. European Journal of Operational Research, 212(1), 141-147.

Levene, H. (1960). Robust tests for equality of variances. In Contributions to Probability and Statistics, I. Olkin, S. G. Ghurye, W. Hoeffding, W. G. Madow, \& H. B. Mann (eds), 278-292. Stanford, California: Stanford University Press.

Li, X.-B., \& Reeves, G. R. (1999). A multiple criteria approach to data envelopment analysis. European Journal of Operational Research, 115, 507-517.

Lovell, C. A. K., \& Rouse, A. P. B. (2003). Equivalent standard DEA models to provide super-efficiency scores. Journal of the Operational Research Society, 54(1), 101-108.

Lu, W.-M., \& Lo, S.-F. (2007). A closer look at the economic-environmental disparities for regional development in China. European Journal of Operational Research, 183(2), 882-894.

Podinovski, V. V. (2004a). Suitability and redundancy of non-homogeneous weight restrictions for measuring the relative efficiency in DEA. European Journal of Operational Research, 154(2), 380-395.

Podinovski, V. V. (2015). DEA models with production trade-offs and weight restrictions. In J. Zhu (Ed.), Data envelopment analysis: A handbook of models and methods (pp. 105-144). New York: Springer Science + Business Media

Podinovski, V. V., \& Thanassoulis, E. (2007). Improving discrimination in data envelopment analysis: Some practical suggestions. Journal of Productivity Analysis, 28(1-2), 117-126.

Podinovski, V.V. (2004b). Production trade-offs and weight restrictions in data envelopment analysis. Journal of the Operational Research Society, 55(12), 1311-1322.

Podinovski, V.V., \& Bouzdine-Chameeva, T. (2013). Weight Restrictions and Free Production in Data Envelopment Analysis. Operations Research, 61(2), 426-437.

Pourmahmoud, J., Hatami-Marbini, A., \& Babazadeh, E. (2016). A comment on a new super-efficiency model in the presence of negative data. The journal of the Operational Research Society, 67, 530-534.

Read, L. E., \& Thanassoulis, E. (2000). Improving the identification of returns to scale in data envelopment analysis. Journal of the Operational Research Society, 51(1), 102-110.

Roll, Y., Cook, W. D., \& Golany, B. (1991). Controlling factor weights in data envelopment analysis. IIE transactions, 23(1), 2-9. 
Saati, S., Hatami-Marbini, A., Agrell, P. J., \& Tavana, M. (2012). A common set of weight approach using an ideal decision making unit in data envelopment analysis. Journal of Industrial and Management Optimization, 8(3), 623-637.

Sarrico, C. S., \& Dyson, R. G. (2004). Restricting virtual weights in data envelopment analysis. European Journal of Operational Research, 159(1), 17-34.

Seiford, L. M., \& Zhu, J. (1999). Infeasibility of super-efficiency data envelopment analysis models. INFOR: Information Systems and Operational Research, 37(2), 174-187.

Sexton, T. R., Silkman, R. H., \& Hogan, A. J. (1986). Data envelopment analysis: Critique and extensions. New Directions for Program Evaluation, (32), 73-105.

Shokouhi, A. H., Hatami-Marbini, A., Tavana, M., \& Saati, S. (2010). A robust optimization approach for imprecise data envelopment analysis. Computers \& Industrial Engineering, 59(3), 387-397.

Shokouhi, A. H., Shahriari, H., Agrell, P. J., \& Hatami-Marbini, A. (2014). Consistent and robust ranking in imprecise data envelopment analysis under perturbations of random subsets of data. $O R$ spectrum, 36(1), 133-160.

Simar, L., \& Wilson, P. W. (2000). Statistical inference in nonparametric frontier models: The state of the art. Journal of productivity analysis, 13(1), 49-78.

Stewart, T. (1994). Data envelopment analysis and multiple criteria decision making: A response. Omega, 22(2), 205-206.

Stewart, T. (1996). Relationships between data envelopment analysis and multicriteria decision analysis. Journal of the Operational Research Society, 47(5), 654-665.

Thompson, R. G., Langemeier, L. N., Lee, C. T., Lee, E., \& Thrall, R. M. (1990). The role of multiplier bounds in efficiency analysis with application to Kansas farming. Journal of econometrics, 46(1-2), 93108.

Thrall, R. M. (1996). Duality, classification and slacks in DEA. Annals of Operations Research, 66(2), 109-138.

Toloo, M. (2012). On finding the most BCC-efficient DMU: A new integrated MIP-DEA model. Applied Mathematical Modelling, 36(11), 5515-5520.

Toloo, M. (2014a). The role of non-Archimedean epsilon in finding the most efficient unit: With an application of professional tennis players. Applied Mathematical Modelling, 38, 5334-5346.

Toloo, M. (2014b). An epsilon-free approach for finding the most efficient unit in DEA. Applied Mathematical Modelling, 38(13), 3182-3192.

Toloo, M. (2014c). Selecting and full ranking suppliers with imprecise data: A new DEA method. The International Journal of Advanced Manufacturing Technology, 74(5-8), 1141-1148.

Toloo, M., \& Tichy, T. (2015). Two alternative approaches for selecting performance measures in data envelopment analysis. Measurement, 65, 29-40.

Toloo, M., Barat, M., \& Masoumzadeh, A. (2015). Selective measures in data envelopment analysis, Annals of Operations Research, 226, 523-642. 
Zhu, J. (1996). Robustness of the efficient DMUs in data envelopment analysis. European Journal of operational research, 90(3), 451-460. 


\section{APPENDIX}

\section{GAMS CODE}

\$title "An Extension of the Multi-Objective DEA Model"

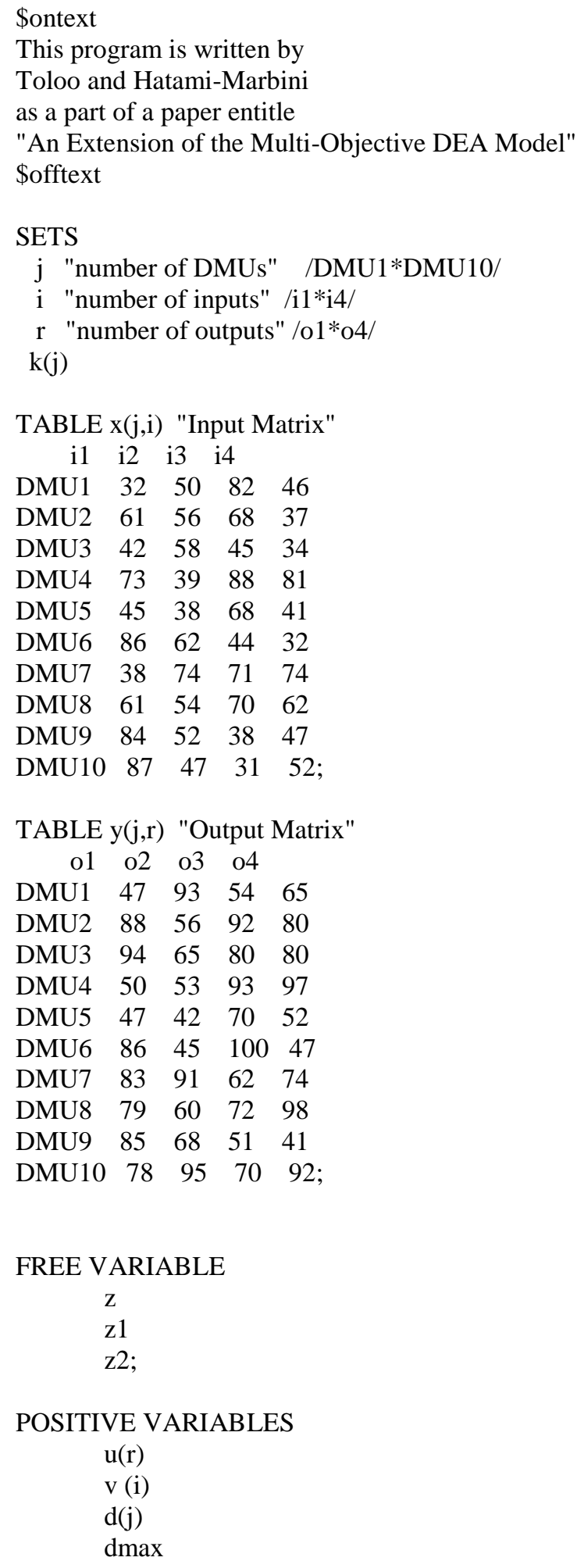

\section{FREE VARIABLE}

Z

$\mathrm{z} 1$

$\mathrm{z} 2$;

POSITIVE VARIABLES

$u(r)$

$\mathrm{v}$ (i)

d(j)

dmax 
eps1;

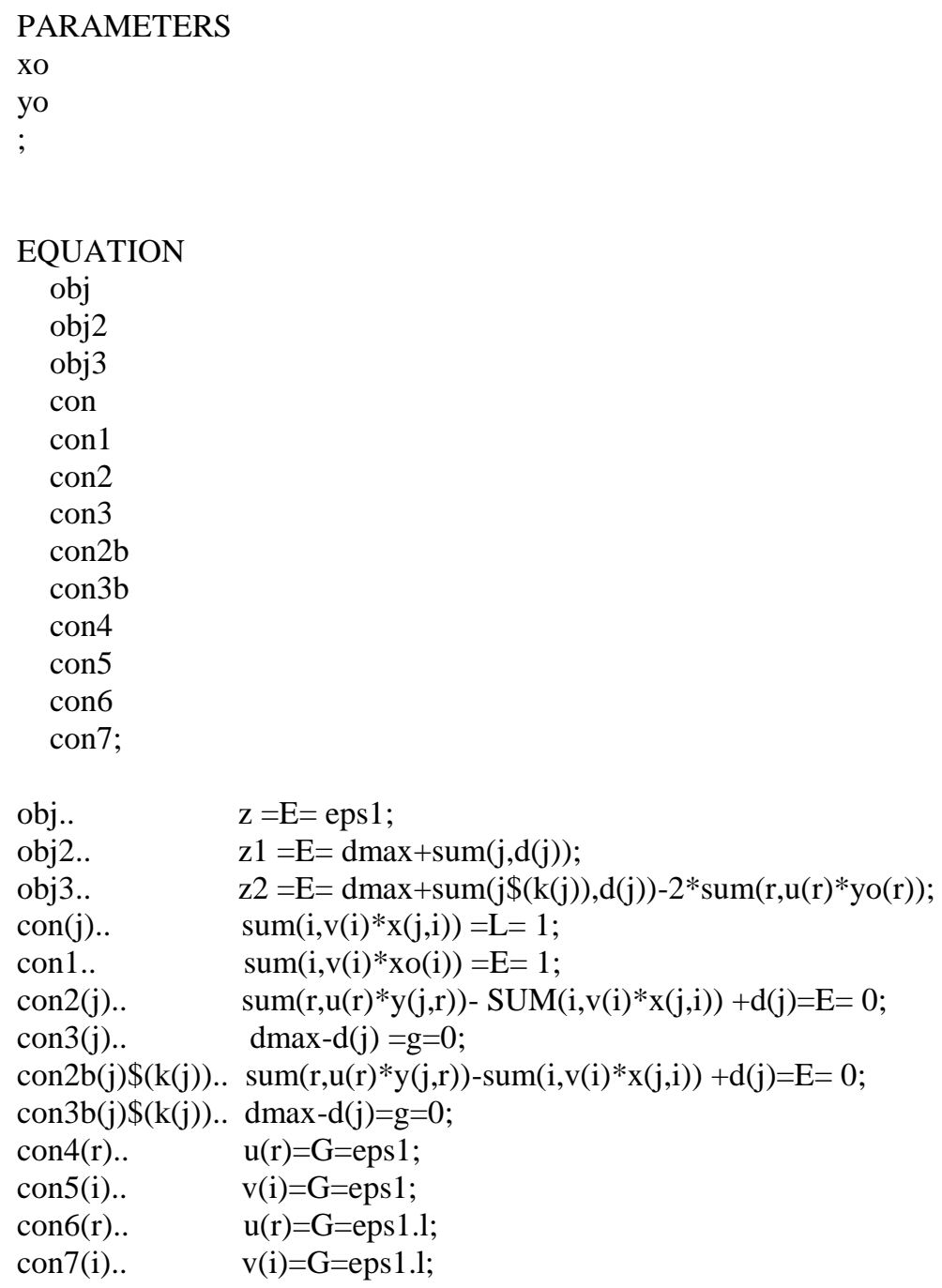

MODEL model_5 /obj, con, con2, con4, con5/;

MODEL model_4 /obj2,con1, con2, con3, con6, con7/;

MODEL model_7 /obj3,con1, con2b, con3b, con6, con7/;

FILE Result/TRIPLE.txt/;

PUT result;

SOLVE model_6 USING LP maximizing z;

PUT 'EPSILON='z.1:10:6 /;

PUT

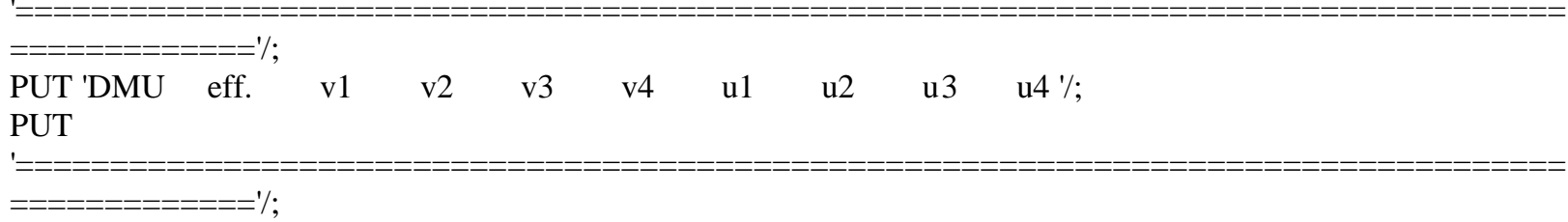

$\operatorname{ALIAS}(\mathrm{j}, 1)$; 


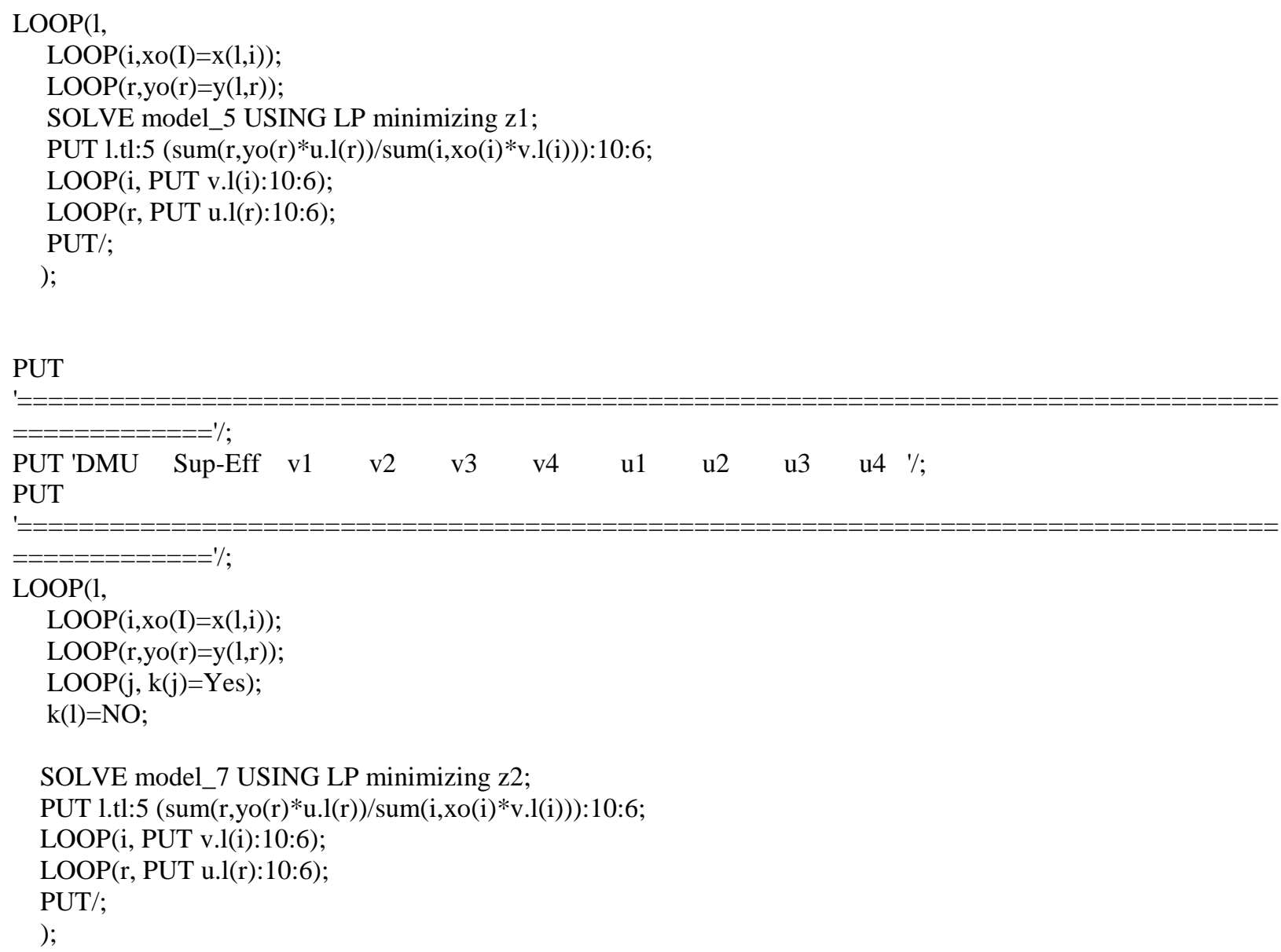




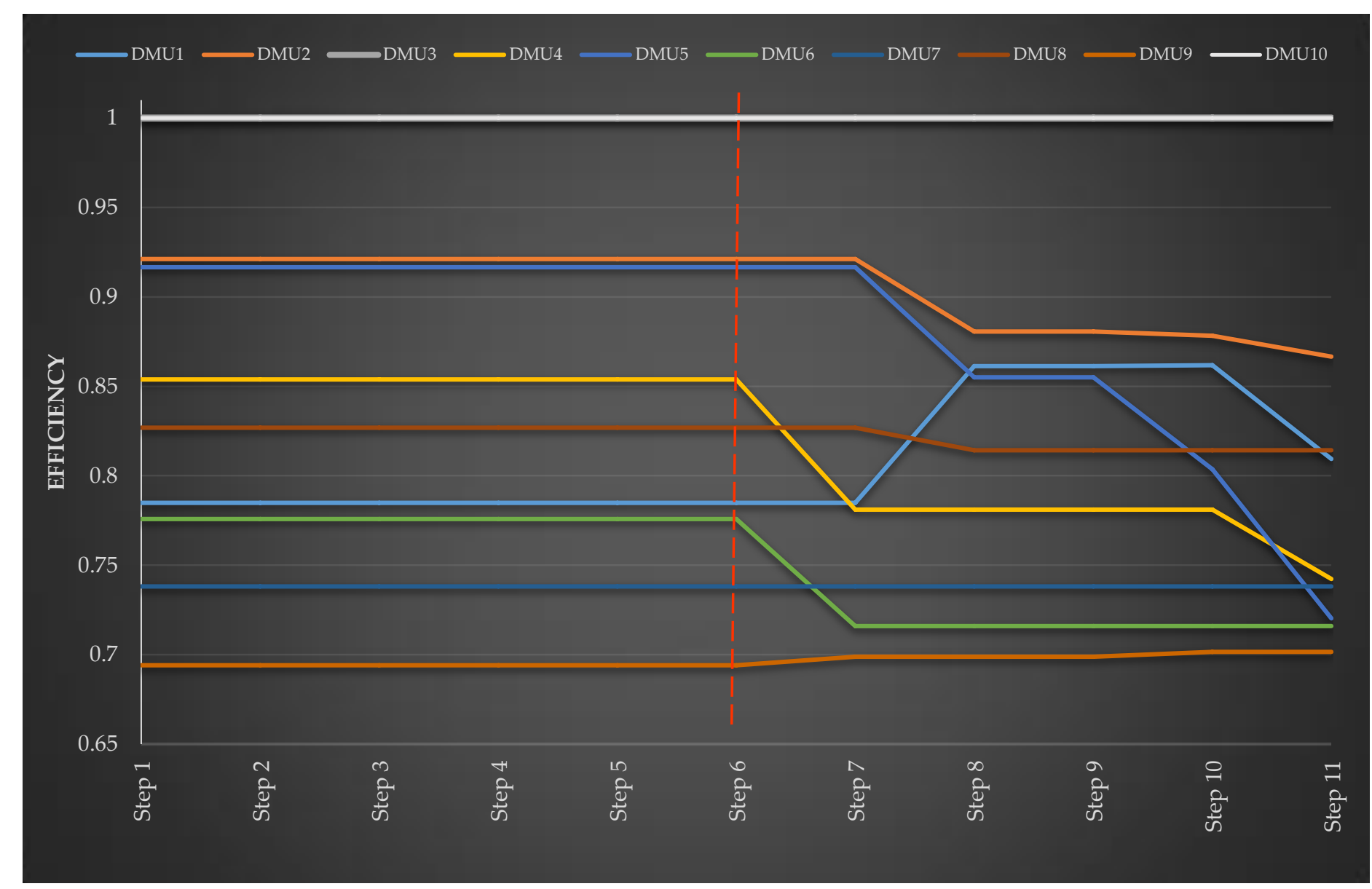

Figure 1. Sensitivity analysis of $w_{2}$ and $w_{3}$ weights in model (4) for 10 DMUs 


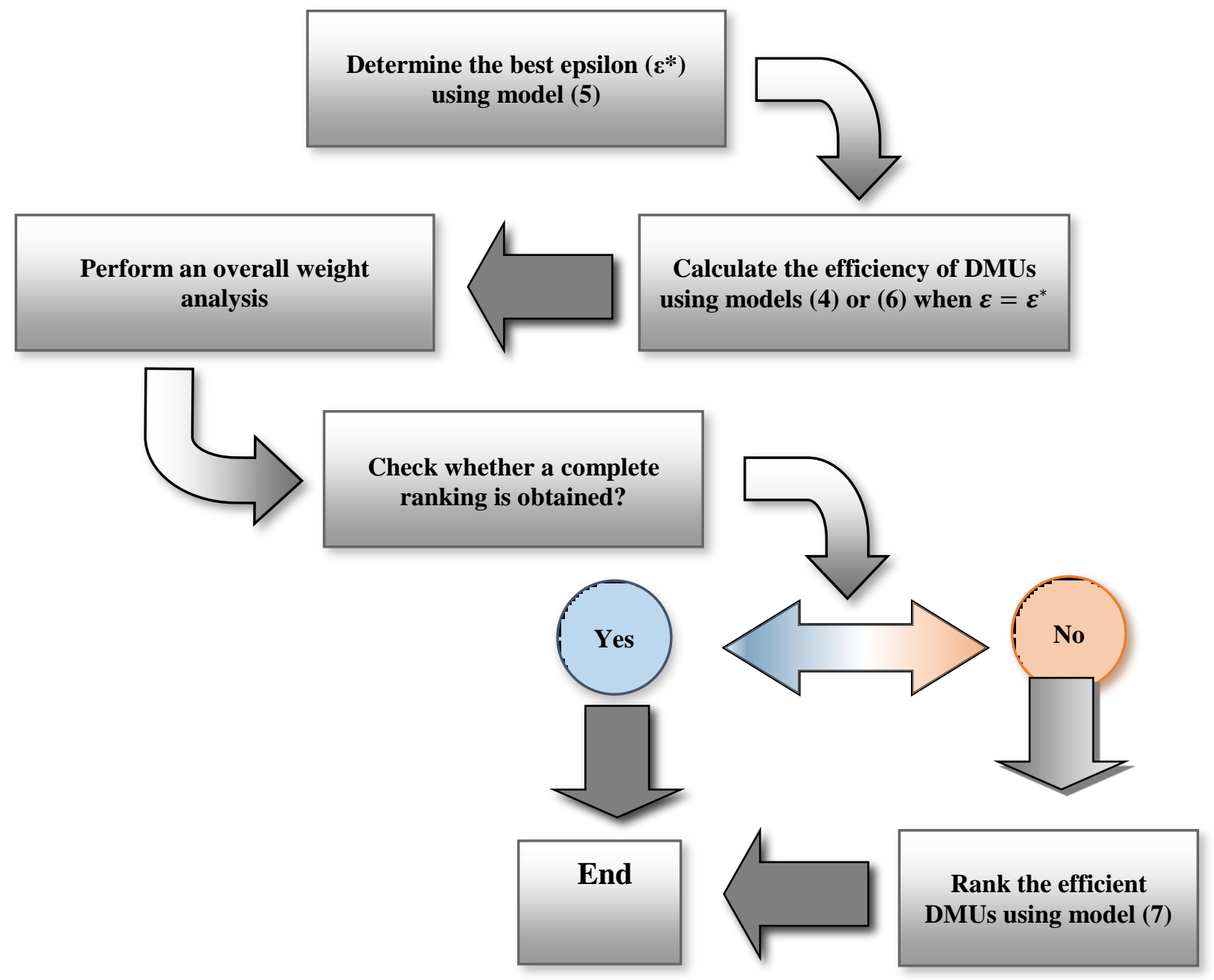

Figure 2. A graphical representation of the proposed methodology 


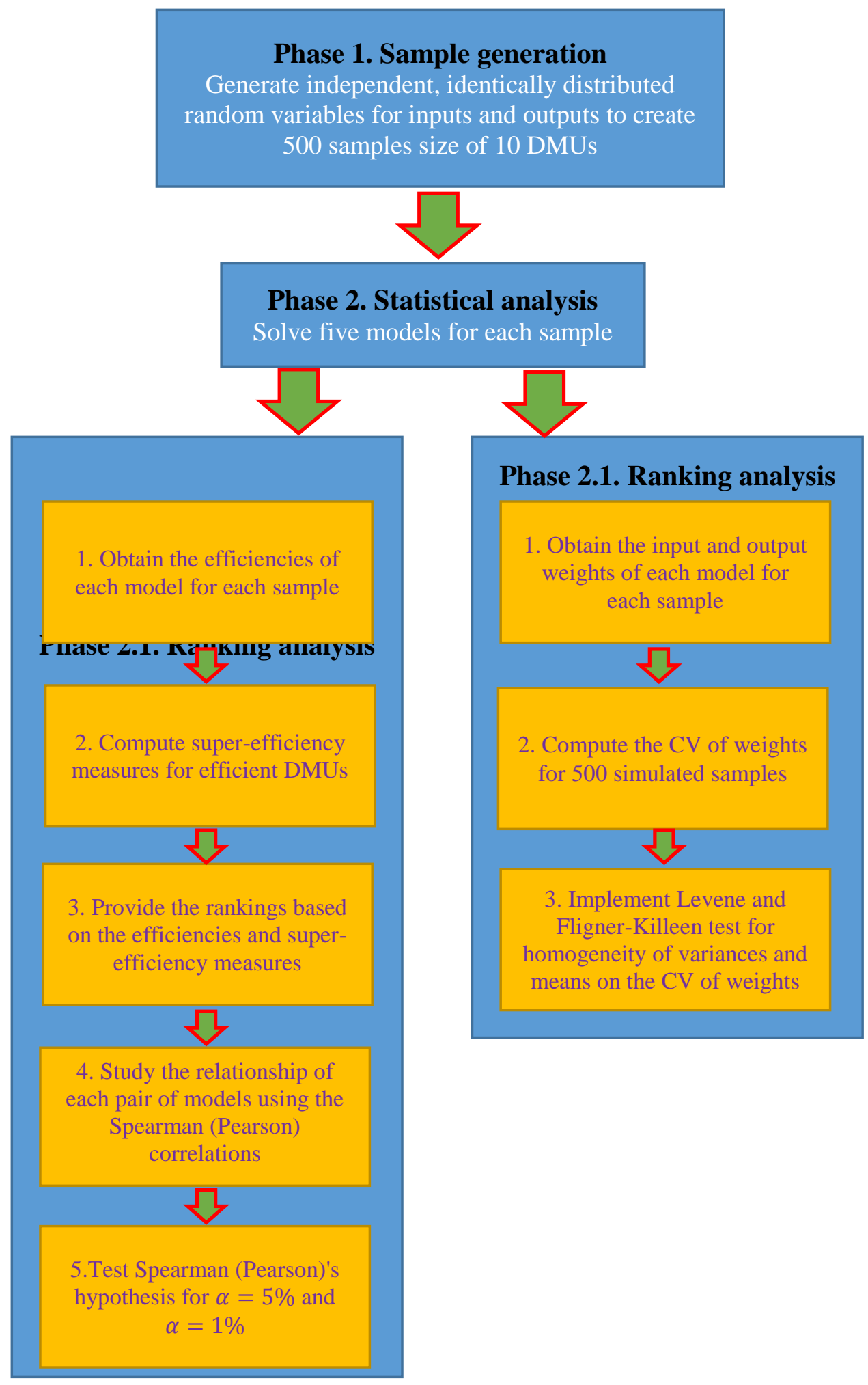

Figure 3. Simulation Steps 
Table 1. Data set and efficiency scores of DEA model (1) for 10 DMUs

\begin{tabular}{|l|c|c|c|c|c|c|c|c|c|}
\hline \multirow{2}{*}{ DMU } & \multicolumn{3}{|l|}{ Inputs } & \multicolumn{1}{|c|}{ Outputs } & \multirow{2}{*}{ Efficiency } \\
\cline { 2 - 9 } & $x_{1}$ & $x_{2}$ & $x_{3}$ & $x_{4}$ & $y_{1}$ & $y_{2}$ & $y_{3}$ & $y_{4}$ & \\
\hline $\mathbf{1}$ & 32 & 50 & 82 & 46 & 47 & 93 & 54 & 65 & 1 \\
\hline $\mathbf{2}$ & 61 & 56 & 68 & 37 & 88 & 56 & 92 & 80 & 1 \\
\hline $\mathbf{3}$ & 42 & 58 & 45 & 34 & 94 & 65 & 80 & 80 & 1 \\
\hline $\mathbf{4}$ & 73 & 39 & 88 & 81 & 50 & 53 & 93 & 97 & 1 \\
\hline $\mathbf{5}$ & 45 & 38 & 68 & 41 & 47 & 42 & 70 & 52 & 1 \\
\hline $\mathbf{6}$ & 86 & 62 & 44 & 32 & 86 & 45 & 100 & 47 & 1 \\
\hline $\mathbf{7}$ & 38 & 74 & 71 & 74 & 83 & 91 & 62 & 74 & 1 \\
\hline $\mathbf{8}$ & 61 & 54 & 70 & 62 & 79 & 60 & 72 & 98 & 1 \\
\hline $\mathbf{9}$ & 84 & 52 & 38 & 47 & 85 & 68 & 51 & 41 & 0.994 \\
\hline $\mathbf{1 0}$ & 87 & 47 & 31 & 52 & 78 & 95 & 70 & 92 & 1 \\
\hline
\end{tabular}

Table 2. Input and output weights, CV measures and efficiency scores for the BiO-MCDEA model with $\varepsilon=0$

\begin{tabular}{|c|c|c|c|c|c|c|c|c|c|c|}
\hline \multirow{2}{*}{ DMU } & \multicolumn{4}{|c|}{ Input weights } & \multicolumn{4}{|c|}{ Output weights } & \multirow{2}{*}{$\mathrm{CV}$} & \multirow{2}{*}{ Efficiency } \\
\hline & $v_{1}$ & $v_{2}$ & $v_{3}$ & $v_{4}$ & $u_{1}$ & $u_{2}$ & $u_{3}$ & $u_{4}$ & & \\
\hline 1 & 0.00454 & 0.01687 & 0.00000 & 0.00024 & 0.00419 & 0.00494 & 0.00579 & 0.00000 & 1.13032 & 0.96831 \\
\hline 2 & 0.00396 & 0.01340 & 0.00000 & 0.00022 & 0.00300 & 0.00436 & 0.00482 & 0.00000 & 1.10765 & 0.95147 \\
\hline 3 & 0.00386 & 0.01433 & 0.00000 & 0.00021 & 0.00356 & 0.00419 & 0.00491 & 0.00000 & 1.13021 & 1 \\
\hline 4 & 0.00344 & 0.01180 & 0.00066 & 0.00285 & 0.00000 & 0.00489 & 0.00797 & 0.00000 & 0.98900 & 1 \\
\hline 5 & 0.00569 & 0.01925 & 0.00000 & 0.00031 & 0.00431 & 0.00626 & 0.00692 & 0.00000 & 1.10805 & 0.94990 \\
\hline 6 & 0.00336 & 0.01137 & 0.00000 & 0.00018 & 0.00255 & 0.00370 & 0.00409 & 0.00000 & 1.10792 & 0.79438 \\
\hline 7 & 0.00291 & 0.01070 & 0.00000 & 0.00132 & 0.00160 & 0.00373 & 0.00493 & 0.00000 & 1.04225 & 0.77852 \\
\hline 8 & 0.00348 & 0.01278 & 0.00000 & 0.00157 & 0.00191 & 0.00446 & 0.00589 & 0.00000 & 1.04233 & 0.84290 \\
\hline 9 & 0.00381 & 0.01289 & 0.00000 & 0.00021 & 0.00289 & 0.00419 & 0.00463 & 0.00000 & 1.10787 & 0.76694 \\
\hline 10 & 0.00402 & 0.01360 & 0.00000 & 0.00022 & 0.00305 & 0.00442 & 0.00489 & 0.00000 & 1.10782 & 1 \\
\hline & & & & & & & & Average & 1.08734 & 0.905242 \\
\hline
\end{tabular}


Table 3. Efficiency scores of the BiO-MCDEA model for three different epsilons

\begin{tabular}{|l|c|c|c|}
\hline \multirow{2}{*}{ DMU } & \multicolumn{3}{|c|}{ Efficiency scores } \\
\cline { 2 - 4 } & $\varepsilon=0.0001$ & $\varepsilon=0.001$ & $\varepsilon=0.002$ \\
\hline $\mathbf{1}$ & $0.96054(4)$ & $0.9219(6)$ & $0.7848(7)$ \\
\hline $\mathbf{2}$ & $0.94822(5)$ & $0.9437(5)$ & $0.9212(3)$ \\
\hline $\mathbf{3}$ & $1(1)$ & $1(1)$ & $1(1)$ \\
\hline $\mathbf{4}$ & $1(1)$ & $1(1)$ & $0.8538(5)$ \\
\hline $\mathbf{5}$ & $0.94738(6)$ & $0.9438(4)$ & $0.9165(4)$ \\
\hline $\mathbf{6}$ & $0.78894(8)$ & $0.8054(8)$ & $0.7758(8)$ \\
\hline $\mathbf{7}$ & $0.76745(9)$ & $0.7397(9)$ & $0.7381(9)$ \\
\hline $\mathbf{8}$ & $0.83737(7)$ & $0.8498(7)$ & $0.8269(6)$ \\
\hline $\mathbf{9}$ & $0.76142(10)$ & $0.6924(10)$ & $0.6940(10)$ \\
\hline $\mathbf{1 0}$ & $1(1)$ & $1(1)$ & $1(1)$ \\
\hline
\end{tabular}

Table 4. Input and output weights, CV measures and efficiency scores for the BiO-MCDEA model with $\varepsilon=0.00238$

\begin{tabular}{|c|c|c|c|c|c|c|c|c|c|c|}
\hline \multirow{2}{*}{ DMU } & \multicolumn{4}{|c|}{ Input weights } & \multicolumn{4}{|c|}{ Output weights } & \multirow{2}{*}{$\mathrm{CV}$} & \multirow{2}{*}{ Efficiency } \\
\hline & $v_{1}$ & $v_{2}$ & $v_{3}$ & $v_{4}$ & $u_{1}$ & $u_{2}$ & $u_{3}$ & $u_{4}$ & & \\
\hline 1 & 0.00289 & 0.01206 & 0.00238 & 0.00238 & 0.00238 & 0.00238 & 0.00550 & 0.00238 & 0.78957 & $0.78484(7)$ \\
\hline 2 & 0.00277 & 0.01038 & 0.00238 & 0.00238 & 0.00238 & 0.00238 & 0.00422 & 0.00238 & 0.71309 & $0.92120(3)$ \\
\hline 3 & 0.00288 & 0.01191 & 0.00238 & 0.00238 & 0.00238 & 0.00238 & 0.00539 & 0.00238 & 0.78304 & $1(1)$ \\
\hline 4 & 0.00275 & 0.01018 & 0.00238 & 0.00238 & 0.00238 & 0.00238 & 0.00406 & 0.00238 & 0.70376 & $0.85376(5)$ \\
\hline 5 & 0.00319 & 0.01572 & 0.00238 & 0.00238 & 0.00238 & 0.00241 & 0.00828 & 0.00238 & 0.92314 & $0.91652(4)$ \\
\hline 6 & 0.00270 & 0.00947 & 0.00238 & 0.00238 & 0.00238 & 0.00238 & 0.00352 & 0.00238 & 0.66858 & $0.77576(8)$ \\
\hline 7 & 0.00477 & 0.00640 & 0.00238 & 0.00238 & 0.00238 & 0.00238 & 0.00238 & 0.00238 & 0.45466 & $0.73810(9)$ \\
\hline 8 & 0.00271 & 0.00964 & 0.00238 & 0.00238 & 0.00238 & 0.00238 & 0.00365 & 0.00238 & 0.67716 & $0.82694(6)$ \\
\hline 9 & 0.00280 & 0.01082 & 0.00238 & 0.00238 & 0.00238 & 0.00238 & 0.00455 & 0.00238 & 0.73411 & $0.69401(10)$ \\
\hline 10 & 0.00287 & 0.01176 & 0.00238 & 0.00238 & 0.00238 & 0.00238 & 0.00527 & 0.00238 & 0.77654 & $1(1)$ \\
\hline & & & & & & & & Average & 0.72236 & 0.851113 \\
\hline
\end{tabular}


Table 5. Input and output weights, CV measures and efficiency scores derived from the weighted MCDEA model with $\varepsilon=0.00238$

\begin{tabular}{|c|c|c|c|c|c|c|c|c|c|c|}
\hline \multirow[b]{2}{*}{ DMU } & \multicolumn{4}{|c|}{ Input weights } & \multicolumn{4}{|c|}{ Output weights } & \multirow[b]{2}{*}{ CV } & \multirow[b]{2}{*}{ Efficiency } \\
\hline & $v_{1}$ & $v_{2}$ & $v_{3}$ & $v_{4}$ & $u_{1}$ & $u_{2}$ & $u_{3}$ & $u_{4}$ & & \\
\hline 1 & 0.00396 & 0.01137 & 0.00238 & 0.00238 & 0.00238 & 0.00387 & 0.00436 & 0.00238 & 0.73590 & $0.86126(5)$ \\
\hline 2 & 0.00277 & 0.01038 & 0.00238 & 0.00238 & 0.00238 & 0.00238 & 0.00422 & 0.00238 & 0.76233 & $0.92120(3)$ \\
\hline 3 & 0.00288 & 0.01191 & 0.00238 & 0.00238 & 0.00238 & 0.00238 & 0.00539 & 0.00238 & 0.83710 & $1(1)$ \\
\hline 4 & 0.00275 & 0.01018 & 0.00238 & 0.00238 & 0.00238 & 0.00238 & 0.00406 & 0.00238 & 0.75235 & $0.85376(6)$ \\
\hline 5 & 0.00319 & 0.01572 & 0.00238 & 0.00238 & 0.00238 & 0.00241 & 0.00828 & 0.00238 & 0.98688 & $0.91652(4)$ \\
\hline 6 & 0.00270 & 0.00947 & 0.00238 & 0.00238 & 0.00238 & 0.00238 & 0.00352 & 0.00238 & 0.71474 & $0.77576(8)$ \\
\hline 7 & 0.00477 & 0.00640 & 0.00238 & 0.00238 & 0.00238 & 0.00238 & 0.00238 & 0.00238 & 0.48605 & $0.73810(9)$ \\
\hline 8 & 0.00271 & 0.00964 & 0.00238 & 0.00238 & 0.00238 & 0.00238 & 0.00365 & 0.00238 & 0.72391 & $0.82694(7)$ \\
\hline 9 & 0.00280 & 0.01082 & 0.00238 & 0.00238 & 0.00238 & 0.00238 & 0.00455 & 0.00238 & 0.78480 & $0.69401(10)$ \\
\hline 10 & 0.00287 & 0.01176 & 0.00238 & 0.00238 & 0.00238 & 0.00238 & 0.00527 & 0.00238 & 0.83016 & $1(1)$ \\
\hline
\end{tabular}

Table 1. Minsum BCC-DEA results of Ghasemi et al. (2014)

\begin{tabular}{|l|c|c|l|l|l|l|l|l|l|}
\hline \multirow{2}{*}{ DMU } & \multicolumn{4}{|c|}{ Input weights } & \multicolumn{3}{|c|}{ Output weights } & \multirow{2}{*}{ Efficiency } \\
\cline { 2 - 10 } & $v_{1}$ & $v_{2}$ & \multicolumn{1}{|c|}{$v_{3}$} & \multicolumn{1}{|c|}{$v_{4}$} & \multicolumn{1}{|c|}{$u_{1}$} & $u_{2}$ & $u_{3}$ & $u_{4}$ & \\
\hline $\mathbf{1}$ & 0.00155 & 0.01901 & 0 & 0 & 0.00762 & 0 & 0.00172 & 0 & 0.765 \\
\hline $\mathbf{2}$ & 0.00368 & 0.01385 & 0 & 0 & 0.0034 & 0.00328 & 0.00307 & 0 & 0.945 \\
\hline $\mathbf{3}$ & 0.00385 & 0.01446 & 0 & 0 & 0.00355 & 0.00343 & 0.00321 & 0 & 1 \\
\hline $\mathbf{4}$ & 0.00314 & 0.0119 & 0.00032 & 0.00344 & 0 & 0.005 & 0.00821 & 0 & 1 \\
\hline $\mathbf{5}$ & 0.00532 & 0.02001 & 0 & 0 & 0.00491 & 0.00475 & 0.00444 & 0 & 1 \\
\hline $\mathbf{6}$ & 0.00313 & 0.01178 & 0 & 0 & 0.00289 & 0.00279 & 0.00261 & 0 & 0.788 \\
\hline $\mathbf{7}$ & 0.00106 & 0.01297 & 0 & 0 & 0.0052 & 0 & 0.00118 & 0 & 0.718 \\
\hline $\mathbf{8}$ & 0.00379 & 0.01424 & 0 & 0 & 0.00349 & 0.00338 & 0.00316 & 0 & 0.89 \\
\hline $\mathbf{9}$ & 0.00358 & 0.01345 & 0 & 0 & 0.0033 & 0.00319 & 0.00298 & 0 & 0.824 \\
\hline $\mathbf{1 0}$ & 0.00379 & 0.01426 & 0 & 0 & 0.0035 & 0.00338 & 0.00316 & 0 & 1 \\
\hline
\end{tabular}

Table 2. Input and output weights and efficiency scores obtained from minsum BCC-DEA model Error! Reference source not found. with $\varepsilon^{*}=\mathbf{0 . 0 0 3 5 5 9}$

\begin{tabular}{|c|c|c|c|c|c|c|c|c|c|}
\hline \multirow[b]{2}{*}{ DMU } & \multicolumn{4}{|c|}{ Input weights } & \multicolumn{4}{|c|}{ Output weights } & \multirow[b]{2}{*}{ Efficiency } \\
\hline & $v_{1}$ & $v_{2}$ & $v_{3}$ & $v_{4}$ & $u_{1}$ & $u_{2}$ & $u_{3}$ & $u_{4}$ & \\
\hline 1 & 0.00356 & 0.00861 & 0.00356 & 0.00356 & & 0.00356 & 0.00432 & 0.00356 & 0.00356 \\
\hline 2 & 0.00356 & 0.00731 & 0.00356 & 0.00356 & & 0.00356 & 0.00479 & 0.00356 & 0.00356 \\
\hline 3 & 0.00356 & 0.00982 & 0.00356 & 0.00356 & & 0.00356 & 0.00387 & 0.00356 & 0.00356 \\
\hline 4 & 0.00356 & 0.00356 & 0.00356 & 0.00356 & & 0.00356 & 0.00617 & 0.00356 & 0.00356 \\
\hline 5 & 0.00379 & 0.01162 & 0.00356 & 0.00356 & & 0.00356 & 0.00356 & 0.00356 & 0.00356 \\
\hline 6 & 0.00356 & 0.00683 & 0.00356 & 0.00356 & & 0.00356 & 0.00497 & 0.00356 & 0.00356 \\
\hline 7 & 0.00356 & 0.00471 & 0.00356 & 0.00356 & & 0.00356 & 0.00575 & 0.00356 & 0.00356 \\
\hline 8 & 0.00356 & 0.00580 & 0.00356 & 0.00356 & & 0.00356 & 0.00535 & 0.00356 & 0.00356 \\
\hline 9 & 0.00356 & 0.00767 & 0.00356 & 0.00356 & & 0.00356 & 0.00466 & 0.00356 & 0.00356 \\
\hline 10 & 0.00356 & 0.00841 & 0.00356 & 0.00356 & & 0.00356 & 0.00439 & 0.00356 & 0.00356 \\
\hline
\end{tabular}


Table 8. Descriptive statistics for the simulated input and output data and the efficiency scores of five models for 500 samples

\begin{tabular}{|c|c|c|c|c|c|c|}
\hline \multicolumn{2}{|c|}{500 samples } & Mean & Median & Min & $\operatorname{Max}$ & STD \\
\hline \multirow[t]{8}{*}{ Data set } & $x_{1}$ & 50.2315 & 50 & 0 & 100 & 28.5387 \\
\hline & $x_{2}$ & 49.9271 & 49 & 0 & 100 & 28.6127 \\
\hline & $x_{3}$ & 50.3845 & 50 & 0 & 100 & 28.8793 \\
\hline & $x_{3}$ & 50.2962 & 51 & 0 & 100 & 29.3373 \\
\hline & $y_{1}$ & 50.2634 & 50 & 0 & 100 & 28.6883 \\
\hline & $y_{2}$ & 51.3056 & 51 & 0 & 100 & 28.6673 \\
\hline & $y_{3}$ & 51.3715 & 51 & 0 & 100 & 29.0708 \\
\hline & $y_{4}$ & 50.5632 & 50 & 0 & 100 & 28.7262 \\
\hline \multirow[t]{5}{*}{ Efficiency } & $\mathrm{CCR}^{e^{*}}$ & 0.8467 & 1 & 0.0586 & 1 & 0.2315 \\
\hline & BiO-MCDEA $^{\varepsilon^{*}}$ & 0.6654 & 0.6467 & 0.0522 & 1 & 0.2640 \\
\hline & TRI-MCDEA $^{\varepsilon^{*}}$ & 0.7191 & 0.7516 & 0.0522 & 1 & 0.2693 \\
\hline & $\mathrm{BiO}^{-M C D E A}{ }^{\varepsilon=0.0001}$ & 0.6917 & 0.6980 & 0.0010 & 1 & 0.2718 \\
\hline & $\mathrm{CCR}^{\varepsilon=0}$ & 0.9427 & 1 & 0.1161 & 1 & 0.1397 \\
\hline
\end{tabular}

Table 9. Descriptive statistics of the simulated weights for five models

\begin{tabular}{|c|c|c|c|c|c|c|c|c|c|}
\hline \multirow{2}{*}{$\begin{array}{c}500 \\
\text { samples }\end{array}$} & \multirow{2}{*}{ Model } & \multicolumn{4}{|c|}{ Input weights } & \multicolumn{4}{|c|}{ Output weights } \\
\hline & & $v_{1}$ & $v_{2}$ & $v_{3}$ & $v_{4}$ & $u_{1}$ & $u_{2}$ & $u_{3}$ & $u_{4}$ \\
\hline \multirow[t]{5}{*}{ Mean } & $\mathbf{C C R}^{\varepsilon^{*}}$ & 0.0122 & 0.0115 & 0.0113 & 0.0135 & 0.0038 & 0.0039 & 0.0041 & 0.0049 \\
\hline & BiO-MCDEA ${ }^{\varepsilon^{*}}$ & 0.0051 & 0.0050 & 0.0051 & 0.0048 & 0.0034 & 0.0034 & 0.0035 & 0.0035 \\
\hline & TRI-MCDEA ${ }^{\varepsilon^{*}}$ & 0.0053 & 0.0051 & 0.0053 & 0.0051 & 0.0035 & 0.0035 & 0.0037 & 0.0037 \\
\hline & BiO-MCDEA $^{\varepsilon=0.0001}$ & 0.0046 & 0.0047 & 0.0046 & 0.0043 & 0.0033 & 0.0033 & 0.0035 & 0.0034 \\
\hline & $\mathrm{CCR}^{\varepsilon=0}$ & 0.0183 & 0.0163 & 0.0161 & 0.0193 & 0.0084 & 0.0082 & 0.0088 & 0.0106 \\
\hline \multirow[t]{5}{*}{ Median } & $\mathbf{C C R}^{\varepsilon^{*}}$ & 0.0029 & 0.0029 & 0.0030 & 0.0031 & 0.0024 & 0.0024 & 0.0024 & 0.0025 \\
\hline & BiO-MCDEA ${ }^{\varepsilon^{*}}$ & 0.0038 & 0.0038 & 0.0039 & 0.0035 & 0.0024 & 0.0024 & 0.0025 & 0.0025 \\
\hline & TRI-MCDEA ${ }^{\varepsilon^{*}}$ & 0.0040 & 0.0039 & 0.0041 & 0.0036 & 0.0025 & 0.0025 & 0.0025 & 0.0025 \\
\hline & BiO-MCDEA $^{\varepsilon=0.0001}$ & 0.0038 & 0.0039 & 0.0037 & 0.0035 & 0.0023 & 0.0022 & 0.0025 & 0.0023 \\
\hline & $\operatorname{CCR}^{\varepsilon=0}$ & 0.0079 & 0.0080 & 0.0082 & 0.0082 & 0.0075 & 0.0072 & 0.0078 & 0.0077 \\
\hline \multirow[t]{5}{*}{ Min } & $\mathbf{C C R}^{\varepsilon^{*}}$ & 0.0009 & 0.0009 & 0.0009 & 0.0009 & 0.0009 & 0.0009 & 0.0009 & 0.0009 \\
\hline & BiO-MCDEA $^{\varepsilon^{*}}$ & 0.0010 & 0.0009 & 0.0009 & 0.0009 & 0.0009 & 0.0009 & 0.0009 & 0.0009 \\
\hline & TRI-MCDEA ${ }^{\varepsilon^{*}}$ & 0.0010 & 0.0009 & 0.0009 & 0.0009 & 0.0009 & 0.0009 & 0.0009 & 0.0009 \\
\hline & BiO-MCDEA $^{\varepsilon=0.0001}$ & 0.0001 & 0.0001 & 0.0001 & 0.0001 & 0.0001 & 0.0001 & 0.0001 & 0.0001 \\
\hline & $\operatorname{CCR}^{\varepsilon=0}$ & 0 & 0 & 0 & 0 & 0 & 0 & 0 & 0 \\
\hline \multirow[t]{5}{*}{ Max } & $\mathbf{C C R}^{\varepsilon^{*}}$ & 4.4717 & 3.4607 & 1.8917 & 4.0470 & 0.1346 & 0.0568 & 0.1592 & 0.7062 \\
\hline & BiO-MCDEA $^{\varepsilon^{*}}$ & 0.0435 & 0.0331 & 0.0859 & 0.0429 & 0.0588 & 0.0387 & 0.0448 & 0.0421 \\
\hline & TRI-MCDEA ${ }^{\varepsilon^{*}}$ & 0.0435 & 0.0375 & 0.0772 & 0.0403 & 0.0587 & 0.0316 & 0.0448 & 0.0421 \\
\hline & BiO-MCDEA $^{\varepsilon=0.0001}$ & 0.0412 & 0.0362 & 0.0880 & 0.0372 & 0.0570 & 0.0431 & 0.0442 & 0.0409 \\
\hline & $\mathrm{CCR}^{\varepsilon=0}$ & 6.9440 & 4.9481 & 2.2000 & 4.7888 & 0.0720 & 0.1250 & 0.2000 & 1 \\
\hline \multirow[t]{5}{*}{ STD } & $\mathbf{C C R}^{\varepsilon^{*}}$ & 0.0857 & 0.0647 & 0.0444 & 0.0775 & 0.0043 & 0.0040 & 0.0048 & 0.0130 \\
\hline & BiO-MCDEA ${ }^{\varepsilon^{*}}$ & 0.0038 & 0.0037 & 0.0039 & 0.0037 & 0.0027 & 0.0025 & 0.0027 & 0.0028 \\
\hline & TRI-MCDEA ${ }^{\varepsilon^{*}}$ & 0.0040 & 0.0039 & 0.0041 & 0.0039 & 0.0029 & 0.0027 & 0.0029 & 0.0030 \\
\hline & BiO-MCDEA $^{\varepsilon=0.0001}$ & 0.0047 & 0.0046 & 0.0047 & 0.0045 & 0.0039 & 0.0038 & 0.0039 & 0.0040 \\
\hline & $\operatorname{CCR}^{\varepsilon=0}$ & 0.1474 & 0.1007 & 0.0609 & 0.1175 & 0.0070 & 0.0071 & 0.0084 & 0.0274 \\
\hline
\end{tabular}


Table 10. Average value for the Spearman and Pearson correlations

\begin{tabular}{|c|c|c|c|c|c|}
\hline & CCR $^{\varepsilon^{*}}$ & BiO-MCDEA $^{\varepsilon^{*}}$ & TRI-MCDEA $^{\varepsilon^{*}}$ & BiO-MCDEA $^{\varepsilon=0.0001}$ & CCR $^{\varepsilon=0}$ \\
\hline CCR $^{\varepsilon^{*}}$ & 1 & 0.556218 & 0.661603 & 0.350871 & 0.940098 \\
\hline BiO-MCDEA $^{\varepsilon^{*}}$ & & 1 & 0.865663 & 0.77708 & 0.48683 \\
\hline TRI-MCDEA $^{\varepsilon^{*}}$ & & & 1 & 0.662238 & 0.593783 \\
\hline BiO-MCDEA $^{\varepsilon=0.0001}$ & & & & 1 & 0.299763 \\
\hline CCR $^{\varepsilon=0}$ & & & & & 1 \\
\hline
\end{tabular}

Table 11. Result of Spearman's and Pearson tests*

\begin{tabular}{|c|c|c|c|c|c|c|}
\hline \multicolumn{2}{|c|}{$\%$ of failing to reject $H_{0}$} & \multicolumn{5}{|c|}{$\alpha=5 \%$} \\
\hline & & $\mathbf{C C R}^{\varepsilon^{*}}$ & BiO-MCDEA ${ }^{\varepsilon^{*}}$ & TRI-MCDEA $^{\varepsilon^{*}}$ & BiO-MCDEA $A^{\varepsilon=0.0001}$ & $\mathbf{C C R}^{\varepsilon=0}$ \\
\hline \multirow{5}{*}{ 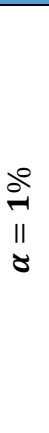 } & $\mathbf{C} \mathbf{C R} \mathbf{R}^{\varepsilon^{*}}$ & 1 & $\begin{array}{c}0.418838 \\
(0.440882)\end{array}$ & $\begin{array}{c}0.603206 \\
(0.623246)\end{array}$ & $\begin{array}{c}0.150301 \\
(0.174349) \\
\end{array}$ & $\begin{array}{c}0.98998 \\
(0.98998) \\
\end{array}$ \\
\hline & BiO-MCDEA ${ }^{\varepsilon^{*}}$ & $\begin{array}{c}0.184369 \\
(0.226453)\end{array}$ & 1 & $\begin{array}{l}0.915832 \\
(0.92986)\end{array}$ & $\begin{array}{c}0.823647 \\
(0.843687)\end{array}$ & $\begin{array}{c}0.324649 \\
(0.344689)\end{array}$ \\
\hline & TRI-MCDEA ${ }^{\varepsilon^{*}}$ & $\begin{array}{l}0.332665 \\
(0.39479) \\
\end{array}$ & $\begin{array}{c}0.787575 \\
(0.813627) \\
\end{array}$ & 1 & $\begin{array}{c}0.599198 \\
(0.619239) \\
\end{array}$ & $\begin{array}{l}0.492986 \\
(0.50501) \\
\end{array}$ \\
\hline & BiO-MCDEA $A^{\varepsilon=0.0001}$ & $\begin{array}{c}0.034068 \\
(0.0501)\end{array}$ & $\begin{array}{c}0.56513 \\
(0.635271)\end{array}$ & $\begin{array}{c}0.322645 \\
(0.372746)\end{array}$ & 1 & $\begin{array}{c}0.118236 \\
(0.134269)\end{array}$ \\
\hline & $\mathbf{C C R}^{\varepsilon=0}$ & $\begin{array}{l}0.965932 \\
(0.96994) \\
\end{array}$ & $\begin{array}{c}0.118237 \\
(0.166333)\end{array}$ & $\begin{array}{c}0.250501 \\
(0.290581)\end{array}$ & $\begin{array}{c}0.02004 \\
(0.032064)\end{array}$ & 1 \\
\hline
\end{tabular}

*Note: The values in the parentheses are related to Pearson test. Besides, the values above and below the diagonal correspond to $\alpha=5 \%$ and $\alpha=1 \%$, repectively.

Table 12. The average of $P$-value for Levene's test

\begin{tabular}{|c|c|c|c|c|c|}
\hline & CCR $^{\varepsilon^{*}}$ & BiO-MCDEA $^{\varepsilon^{*}}$ & TRI-MCDEA $^{\varepsilon^{*}}$ & BiO-MCDEA $^{\varepsilon=0.0001}$ & CCR $^{\varepsilon=0}$ \\
\hline CCR $^{\max \varepsilon}$ & 1 & 0.115738 & 0.108247 & 0.163207 & 0.304061 \\
\hline BiO-MCDEA $^{\text {max } \varepsilon}$ & & 1 & 0.673899 & 0.370797 & 0.275578 \\
\hline TRI-MCDEA $^{\text {max } \varepsilon}$ & & & 1 & 0.350569 & 0.2495 \\
\hline BiO-MCDEA $^{\varepsilon=0.0001}$ & & & & 1 & 0.32084 \\
\hline CCR $^{\varepsilon=0}$ & & & & & 1 \\
\hline
\end{tabular}

Table 13. Result of the two-sided and one-sided $\left(\sigma_{1}^{2}<\sigma_{2}^{2}\right)$ Levene's test*

\begin{tabular}{|c|c|c|c|c|c|c|}
\hline \multicolumn{2}{|c|}{$\%$ of failing to reject $H_{0}$} & \multicolumn{5}{|c|}{$\alpha=5 \%$} \\
\hline & & $\mathbf{C C R}^{\varepsilon^{*}}$ & BiO-MCDEA ${ }^{\varepsilon^{*}}$ & TRI-MCDEA $^{\varepsilon^{*}}$ & BiO-MCDEA $^{\varepsilon=0.0001}$ & $\mathbf{C C R}^{\varepsilon=0}$ \\
\hline \multirow{5}{*}{$\begin{array}{l}\stackrel{\partial}{\circ} \\
\text { II } \\
\text { ठ }\end{array}$} & $\mathbf{C C R}^{\max \varepsilon}$ & 1 & $\begin{array}{c}0.509018 \\
(0.328657)\end{array}$ & $\begin{array}{c}0.492986 \\
(0.276553)\end{array}$ & $\begin{array}{c}0.59519 \\
(0.440882)\end{array}$ & $\begin{array}{c}0.829659 \\
(0.713427) \\
\end{array}$ \\
\hline & BiO-MCDEA ${ }^{\max \varepsilon}$ & $\begin{array}{c}0.781563 \\
(0.687375)\end{array}$ & 1 & $\begin{array}{c}0.993988 \\
(0.983968)\end{array}$ & $\begin{array}{c}0.817635 \\
(0.733467)\end{array}$ & $\begin{array}{c}0.733467 \\
(0.619239)\end{array}$ \\
\hline & TRI-MCDEA $^{\max \varepsilon}$ & $\begin{array}{c}0.765531 \\
(0.675351)\end{array}$ & $\begin{array}{c}0.997996 \\
(0.997996)\end{array}$ & 1 & $\begin{array}{c}0.813627 \\
(0.719439)\end{array}$ & $\begin{array}{c}0.717435 \\
(0.589178) \\
\end{array}$ \\
\hline & BiO-MCDEA $A^{\varepsilon=0.0001}$ & $\begin{array}{c}0.801603 \\
(0.719439)\end{array}$ & $\begin{array}{c}0.925852 \\
(0.885772)\end{array}$ & $\begin{array}{c}0.91984 \\
(0.87976) \\
\end{array}$ & 1 & $\begin{array}{c}0.747495 \\
(0.645291) \\
\end{array}$ \\
\hline & $\mathbf{C C R}^{\varepsilon=0}$ & $\begin{array}{c}0.931864 \\
(0.891784)\end{array}$ & $\begin{array}{c}0.86974 \\
(0.821643)\end{array}$ & $\begin{array}{c}0.857715 \\
(0.807615)\end{array}$ & $\begin{array}{c}0.88978 \\
(0.835671)\end{array}$ & 1 \\
\hline
\end{tabular}

*Note: The values in the parentheses are related to Pearson test. Besides, the values above and below the diagonal correspond to $\alpha=5 \%$ and $\alpha=1 \%$, repectively. 
Table 14. The average of $P$-value for Fligner-Killeen test

\begin{tabular}{|c|c|c|c|c|c|}
\hline & CCR $^{\varepsilon^{*}}$ & BiO-MCDEA $^{\varepsilon^{*}}$ & TRI-MCDEA $^{\varepsilon^{*}}$ & BiO-MCDEA $^{\varepsilon=0.0001}$ & CCR $^{\varepsilon=0}$ \\
\hline CCR $^{\max \varepsilon}$ & 1 & 0.130934 & 0.115899 & 0.169777 & 0.326943 \\
\hline BiO-MCDEA $^{\max \varepsilon}$ & & 1 & 0.643206 & 0.376426 & 0.325282 \\
\hline TRI-MCDEA $^{\max \varepsilon}$ & & & 1 & 0.369938 & 0.284028 \\
\hline BiO-MCDEA $^{\varepsilon=0.0001}$ & & & & 1 & 0.326273 \\
\hline CCR $^{\varepsilon=0}$ & & & & & 1 \\
\hline
\end{tabular}

Table 15. Result of the two-sided and one-sided Fligner-Killeen test $\left(\mu_{1}<\mu_{2}\right)^{*}$

\begin{tabular}{|c|c|c|c|c|c|c|}
\hline \multicolumn{2}{|c|}{$\%$ of failing to reject $H_{0}$} & \multicolumn{5}{|c|}{$\alpha=\mathbf{5} \%$} \\
\hline & & $\mathbf{C C R}^{\varepsilon^{*}}$ & $\mathbf{B i O}-M C D E A^{\varepsilon^{*}}$ & TRI-MCDEA ${ }^{\varepsilon^{*}}$ & BiO-MCDEA ${ }^{\varepsilon=0.0001}$ & $\operatorname{CCR}^{\varepsilon=0}$ \\
\hline \multirow{5}{*}{ 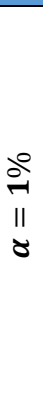 } & $\mathbf{C C R}^{\max \varepsilon}$ & 1 & $\begin{array}{c}0.432866 \\
(0.320641) \\
\end{array}$ & $\begin{array}{c}0.41483 \\
(0.296593) \\
\end{array}$ & $\begin{array}{c}0.476954 \\
(0.382766) \\
\end{array}$ & $\begin{array}{c}0.797595 \\
(0.673347) \\
\end{array}$ \\
\hline & BiO-MCDEA ${ }^{\max \varepsilon}$ & $\begin{array}{c}0.717435 \\
(0.581162)\end{array}$ & 1 & $\begin{array}{c}0.995992 \\
(0.977956)\end{array}$ & $\begin{array}{c}0.789579 \\
(0.699399)\end{array}$ & $\begin{array}{c}0.741483 \\
(0.645291)\end{array}$ \\
\hline & TRI-MCDEA $^{\max \varepsilon}$ & $\begin{array}{c}0.687375 \\
(0.577154) \\
\end{array}$ & $\begin{array}{c}0.997996 \\
(0.995992)\end{array}$ & 1 & $\begin{array}{c}0.785571 \\
(0.705411) \\
\end{array}$ & $\begin{array}{c}0.731463 \\
(0.631263) \\
\end{array}$ \\
\hline & BiO-MCDEA ${ }^{\varepsilon=0.0001}$ & $\begin{array}{c}0.701403 \\
(0.603206)\end{array}$ & $\begin{array}{c}0.921844 \\
(0.865732)\end{array}$ & $\begin{array}{c}0.903808 \\
(0.867736)\end{array}$ & 1 & $\begin{array}{c}0.723447 \\
(0.647295) \\
\end{array}$ \\
\hline & $\operatorname{CCR}^{\varepsilon=0}$ & $\begin{array}{c}0.93988 \\
(0.903808) \\
\end{array}$ & $\begin{array}{c}0.881764 \\
(0.825651) \\
\end{array}$ & $\begin{array}{c}0.877756 \\
(0.813627) \\
\end{array}$ & $\begin{array}{c}0.885772 \\
(0.829659) \\
\end{array}$ & 1 \\
\hline
\end{tabular}

*Note: The values in the parentheses are related to Pearson test. Besides, the values above and below the diagonal correspond to $\alpha=5 \%$ and $\alpha=1 \%$, repectively. 
Table 16. Data for $25 \mathrm{EU}$ countries

\begin{tabular}{|c|c|c|c|c|c|}
\hline \multirow{2}{*}{ DMUs } & \multicolumn{3}{|c|}{ Inputs } & \multicolumn{2}{|c|}{ Outputs } \\
\hline & $x_{1}$ & $x_{2}$ & $x_{3}$ & $y_{1}$ & $y_{2}$ \\
\hline Austria & 225 & 8810 & $31,887,710$ & 66.793 & 6.5 \\
\hline Belgium & 362 & 2242 & $56,797,576$ & 6.083 & 3.3 \\
\hline Bulgaria & 146 & 1087 & $40,591,231$ & 9.808 & 0.6 \\
\hline Cyprus & 13 & 98 & $5,089,082$ & 0.073 & 2.0 \\
\hline Czech Republic & 425 & 2425 & $85,968,002$ & 6.783 & 3.4 \\
\hline Denmark & 408 & 3242 & $23,912,314$ & 27.390 & 0.4 \\
\hline Finland & 661 & 7887 & $37,069,940$ & 25.777 & 2.3 \\
\hline France & 1125 & 19,811 & $128,660,709$ & 13.547 & 6.0 \\
\hline Germany & 1997 & 27,693 & $391,714,624$ & 16.200 & 5.7 \\
\hline Greece & 162 & 1861 & $63,246,705$ & 12.276 & 1.1 \\
\hline Hungary & 270 & 1854 & $23,844,843$ & 6.988 & 3.1 \\
\hline Ireland & 124 & 641 & $19,951,911$ & 13.925 & 1.9 \\
\hline Italy & 1201 & 16,026 & $208,982,856$ & 20.536 & 3.8 \\
\hline Latvia & 111 & 1567 & $3,532,491$ & 49.232 & 1.2 \\
\hline Lithuania & 114 & 874 & $7,573,712$ & 5.505 & 4.2 \\
\hline Luxembourg & 15 & 121 & $2,488,229$ & 3.678 & 2.1 \\
\hline Netherlands & 443 & 3148 & $83,834,170$ & 9.152 & 4.2 \\
\hline Poland & 943 & 6265 & $202,011,597$ & 5.804 & 4.8 \\
\hline Portugal & 280 & 4734 & $30,902,050$ & 33.267 & 3.6 \\
\hline Romania & 275 & 5270 & $73,956,515$ & 27.916 & 1.6 \\
\hline Slovakia & 201 & 1214 & $32,140,581$ & 17.880 & 8.6 \\
\hline Slovenia & 100 & 887 & $8,216,051$ & 36.783 & 1.9 \\
\hline Spain & 1143 & 12,091 & $150,707,494$ & 25.747 & 3.5 \\
\hline Sweden & 821 & 15,819 & $21,103,878$ & 56.378 & 7.3 \\
\hline United Kingdom & 1140 & 6214 & $217,404,830$ & 6.664 & 2.7 \\
\hline
\end{tabular}


Table 17. Efficiency results of 25 countries for different models and their ranks

\begin{tabular}{|c|c|c|c|c|c|c|}
\hline \multirow[b]{2}{*}{ DMU } & \multicolumn{3}{|c|}{ Proposed model $\left(\varepsilon^{*}=0.000122\right)$} & \multirow{2}{*}{$\begin{array}{l}\varepsilon=0 \\
\mathrm{CCR}\end{array}$} & \multirow{2}{*}{\begin{tabular}{l}
\multicolumn{1}{c}{$=\mathbf{1}^{-\mathbf{5}}$} \\
BiO- \\
MCDEA
\end{tabular}} & \multirow{2}{*}{\begin{tabular}{l}
\multicolumn{1}{c}{$\boldsymbol{\varepsilon}=\mathbf{0}$} \\
BiO- \\
MCDEA
\end{tabular}} \\
\hline & CCR & $\begin{array}{l}\text { BiO- } \\
\text { MCDEA }\end{array}$ & $\begin{array}{l}\text { TRI- } \\
\text { MCDEA }\end{array}$ & & & \\
\hline Austria & $1(1)$ & $0.9663(4)$ & $0.9663(3)$ & $1(1)$ & $0.7183(8)$ & $0.7183(8)$ \\
\hline Belgium & $0.4196(20)$ & $0.3523(16)$ & $0.3523(15)$ & $0.4197(22)$ & $0.3523(15)$ & $0.3523(14)$ \\
\hline Bulgaria & $0.3508(22)$ & $0.1157(25)$ & $0.1157(25)$ & $0.5964(20)$ & $0.1157(25)$ & $0.1157(25)$ \\
\hline Cyprus & $0.4528(18)$ & $0.1357(23)$ & $0.1357(23)$ & $0.6882(16)$ & $0.1357(24)$ & $0.1357(24)$ \\
\hline Czech Republic & $0.1256(25)$ & $0.1256(24)$ & $0.1256(24)$ & $0.3802(23)$ & $0.1646(22)$ & $0.1646(22)$ \\
\hline Denmark & $0.4207(19)$ & $0.4067(15)$ & $0.4067(14)$ & $0.5240(21)$ & $0.2311(19)$ & $0.1948(21)$ \\
\hline Finland & $0.1814(24)$ & $0.1651(21)$ & $0.1651(21)$ & $0.2455(25)$ & $0.2016(21)$ & $0.2016(20)$ \\
\hline France & $1(1)$ & $1(1)$ & $0.8996(5)$ & $1(1)$ & $1(1)$ & $1(1)$ \\
\hline Germany & $0.6764(13)$ & $0.6734(11)$ & $0.6734(10)$ & $0.8355(12)$ & $0.6734(9)$ & $0.6734(9)$ \\
\hline Greece & $0.4118(21)$ & $0.1595(22)$ & $0.1595(22)$ & $0.6792(17)$ & $0.1595(23)$ & $0.1595(23)$ \\
\hline Hungary & $0.6694(15)$ & $0.5804(12)$ & $0.5804(11)$ & $0.6694(18)$ & $0.5804(11)$ & $0.5804(11)$ \\
\hline Ireland & $0.6671(16)$ & $0.2705(19)$ & $0.2705(19)$ & $0.9193(9)$ & $0.2705(18)$ & $0.2705(18)$ \\
\hline Italy & $0.8945(9)$ & $0.8543(8)$ & $0.8543(7)$ & $0.9152(10)$ & $0.8543(6)$ & $0.8543(6)$ \\
\hline Latvia & $1(1)$ & $1(1)$ & $1(1)$ & $1(1)$ & $0.645(10)$ & $0.6016(10)$ \\
\hline Lithuania & $0.7546(11)$ & $0.541(13)$ & $0.541(13)$ & $0.7551(15)$ & $0.4568(13)$ & $0.4464(13)$ \\
\hline Luxembourg & $0.2680(23)$ & $0.2258(20)$ & $0.2258(20)$ & $0.2823(24)$ & $0.2258(20)$ & $0.2258(19)$ \\
\hline Netherlands & $0.5850(17)$ & $0.5159(14)$ & $0.3321(16)$ & $0.6541(19)$ & $0.5159(12)$ & $0.5159(12)$ \\
\hline Poland & $0.6758(14)$ & $0.3271(17)$ & $0.3271(17)$ & $0.8153(13)$ & $0.3271(16)$ & $0.3271(15)$ \\
\hline Portugal & $0.9836(7)$ & $0.944(5)$ & $0.944(4)$ & $0.9836(8)$ & $0.9172(3)$ & $0.9172(3)$ \\
\hline Romania & $1(1)$ & $0.8963(6)$ & $0.8963(6)$ & $1(1)$ & $0.8963(4)$ & $0.8963(4)$ \\
\hline Slovakia & $0.9317(8)$ & $0.8824(7)$ & $0.5689(12)$ & $1(1)$ & $0.8778(5)$ & $0.8778(5)$ \\
\hline Slovenia & $0.8055(10)$ & $0.8055(10)$ & $0.8055(9)$ & $0.8780(11)$ & $0.7317(7)$ & $0.7317(7)$ \\
\hline Spain & $1(1)$ & $1(1)$ & $1(1)$ & $1(1)$ & $1(1)$ & $1(1)$ \\
\hline Sweden & $1(1)$ & $0.8241(9)$ & $0.8241(8)$ & 1(1) & $0.3967(14)$ & $0.3145(17)$ \\
\hline United Kingdom & $0.6861(12)$ & $0.3217(18)$ & $0.3217(18)$ & $0.7836(14)$ & $0.3217(17)$ & $0.3217(16)$ \\
\hline
\end{tabular}


Table 18. Input and output weights of different models for the case study

\begin{tabular}{|c|c|c|c|c|c|c|}
\hline \multirow{2}{*}{ Model } & \multirow{2}{*}{ Measure } & \multicolumn{3}{|c|}{ Input weights } & \multicolumn{2}{|c|}{ Output weights } \\
\hline & & $v_{1}$ & $v_{2}$ & $v_{3}$ & $u_{1}$ & $u_{2}$ \\
\hline \multirow{4}{*}{$\begin{array}{c}\text { CCR } \\
(\text { Maximum } \varepsilon)\end{array}$} & Average & 2.1349 & 1.6704 & 0.0002 & 0.0171 & 0.0865 \\
\hline & Median & 0.0001 & 1.6545 & 0.0001 & 0.0188 & 0.0883 \\
\hline & Min & 0.0001 & 0.0001 & 0.0001 & 0.0001 & 0.0001 \\
\hline & Max & 20.0042 & 5.7131 & 0.0006 & 0.0590 & 0.2264 \\
\hline \multirow{4}{*}{$\begin{array}{l}\text { BiO-MCDEA } \\
(\text { Maximum } \varepsilon \text { ) }\end{array}$} & Average & 0.8399 & 1.0019 & 0.0001 & 0.0171 & 0.0679 \\
\hline & Median & 0.0001 & 1.1620 & 0.0001 & 0.0188 & 0.0663 \\
\hline & Min & 0.0001 & 0.0001 & 0.0001 & 0.0001 & 0.0367 \\
\hline & Max & 10.5614 & 2.1651 & 0.0003 & 0.0337 & 0.1113 \\
\hline \multirow{4}{*}{$\begin{array}{l}\text { TRI-MCDEA } \\
(\text { Maximum } \varepsilon \text { ) }\end{array}$} & Average & 0.8641 & 0.9394 & 0.0002 & 0.0162 & 0.0663 \\
\hline & Median & 0.0001 & 0.8117 & 0.0001 & 0.0141 & 0.0620 \\
\hline & Min & 0.0001 & 0.0001 & 0.0001 & 0.0001 & 0.0367 \\
\hline & Max & 10.5614 & 2.3766 & 0.0003 & 0.0337 & 0.1113 \\
\hline \multirow{4}{*}{$\begin{array}{c}\text { CCR } \\
(\varepsilon=0)\end{array}$} & Average & 12.2265 & 2.4377 & 0.0001 & 0.0205 & 0.0980 \\
\hline & Median & 0.0000 & 1.4852 & 0.0000 & 0.0186 & 0.0970 \\
\hline & Min & 0.0000 & 0.0000 & 0.0000 & 0.0000 & 0.0000 \\
\hline & Max & 67.4615 & 9.9833 & 0.0006 & 0.0828 & 0.3441 \\
\hline \multirow{4}{*}{$\begin{array}{c}\text { BiO-MCDEA } \\
\left(\varepsilon=10^{-5}\right)\end{array}$} & Average & 1.9474 & 1.0196 & 0.0001 & 0.0162 & 0.0622 \\
\hline & Median & 0.0000 & 1.1736 & 0.0001 & 0.0154 & 0.0663 \\
\hline & Min & 0.0000 & 0.1900 & 0.0000 & 0.0055 & 0.0098 \\
\hline & Max & 19.4962 & 2.1651 & 0.0003 & 0.0337 & 0.1113 \\
\hline \multirow{4}{*}{$\begin{array}{c}\text { BiO-MCDEA } \\
(\varepsilon=0)\end{array}$} & Average & 2.0458 & 1.0148 & 0.0001 & 0.0160 & 0.0617 \\
\hline & Median & 0.0000 & 1.0972 & 0.0001 & 0.0141 & 0.0663 \\
\hline & Min & 0.0000 & 0.1900 & 0.0000 & 0.0049 & 0.0051 \\
\hline & Max & 20.7458 & 2.1651 & 0.0003 & 0.0337 & 0.1113 \\
\hline
\end{tabular}

